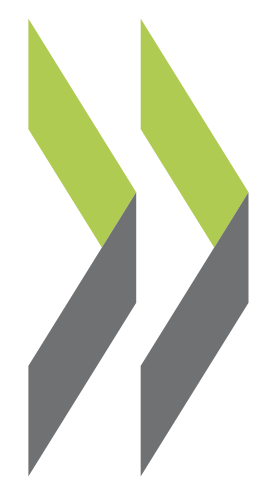

OECD Science, Technology and Industry Working Papers $2002 / 13$

\title{
The Contribution of ICT to Production Efficiency
} in Italy: Firm-Level Evidence Using Data Envelopment Carlo Milana, Analysis and Econometric Estimations 
Organisation de Coopération et de Développement Economiques

Organisation for Economic Co-operation and Development

13-Sep-2002

DIRECTORATE FOR SCIENCE, TECHNOLOGY AND INDUSTRY

English text only

STI Working Paper 2002/13

THE CONTRIBUTION OF ICT TO PRODUCTION EFFICIENCY IN ITALY:

FIRM-LEVEL EVIDENCE USING DATA ENVELOPMENT ANALYSIS AND ECONOMETRIC ESTIMATIONS

Carlo Milana and Alessandro Zeli 


\section{STI Working Paper Series}

The Working Paper series of the OECD Directorate for Science, Technology and Industry is designed to make available to a wider readership selected studies prepared by staff in the Directorate or by outside consultants working on OECD projects. The papers included in the series cover a broad range of issues, of both a technical and policy-analytical nature, in the areas of work of the DSTI. The Working Papers are generally available only in their original language - English or French - with a summary in the other.

Comment on the papers is invited, and should be sent to the Directorate for Science, Technology and Industry, OECD, 2 rue André Pascal, 75775 Paris Cedex 16, France.

The opinions expressed in these papers are the sole responsibility of the author(s) and do not necessarily reflect those of the OECD or of the governments of its member countries.

http://www.oecd.org/sti/working-papers 
DSTI/DOC(2002)13

\title{
THE CONTRIBUTION OF ICT TO PRODUCTION EFFICIENCY IN ITALY: FIRM-LEVEL EVIDENCE USING DATA ENVELOPMENT ANALYSIS AND ECONOMETRIC ESTIMATIONS
}

\author{
Carlo Milana* and Alessandro Zeli**
}

This paper examines the impact of information and communications technologies (ICTs) on technical production efficiency in a wide range of Italian industries. Technical efficiency, defined as the firm's distance from the production efficiency frontier, is one important component of productivity. Assessing the role of ICTs in the organisation and control of production processes may be of primary interest for those firms that are trying to rationalise their production organisation and techniques. The survey of firms examined, the Italian ISTAT SCI covering all firms with at least 20 employees, offers an opportunity to test the hypothesis that ICTs, in both hardware and software components, can positively influence production performance. The analysis is carried out within industries defined by the OECD STAN database, to ease international comparability of the empirical results. Technical efficiency of each individual firm is measured by means of data envelopment analysis, a non-parametric technique that is well known in the field of operations research. The correlation between ICT and technical efficiency is examined using cross-sectional regressions run on firm-level data within each industry. The main conclusion is that this correlation is not significantly rejected in the majority of the industrial sectors considered. In general, positive correlations are not rejected in all four groups of industries defined on the basis of R\&D intensity of production. However, technical efficiency does not seem to be affected by ICT in a significant share of high R\&D intensity industries. This paradoxical result can be explained by noting that almost all firms in these industries already operate at high relative levels of technical efficiency; there is little margin for further gains through increases in the ICT intensity of production.

J.E.L. classification: D2, L2, O4

Keywords: ICT, Technical efficiency, Productivity

\footnotetext{
* Istituto di Studi e Analisi Economica, Piazza Indipendenza, 4, 00185 Rome; tel. +39-06-44482300, FAX: +39-06- 44482219; E-mail: c.milana@isae.it.

** Istituto Nazionale di Statistica, Via Tuscolana, 1782, 00100 Rome; tel. +39-06-72976165, FAX: +39-06-2970798; E-mail: zeli@istat.it.
}

The paper represents the views of the authors and does not necessarily reflect the opinions of the affiliating institutions. 


\title{
LA CONTRIBUTION DES TIC A L'EFFICIENCE DE LA PRODUCTION EN ITALIE - ELEMENTS AU NIVEAU DE L'ENTREPRISE OBTENUS PAR ANALYSE DE L'ENVELOPPEMENT DES DONNEES ET ESTIMATIONS ECONOMETRIQUES
}

\author{
Carlo Milana* and Alessandro Zeli ${ }^{* *}$
}

Ce rapport analyse l'incidence des technologies de l'information et des communications (TIC) sur l'efficience de la production technique dans un large éventail d'industries italiennes. L'efficience technique, définie comme l'éloignement de l'entreprise par rapport à la frontière de l'efficience de la production, est une composante importante de la productivité. L'évaluation du rôle des TIC dans l'organisation et le contrôle des processus de production peut être d'un intérêt majeur pour les entreprises qui s'efforcent de rationaliser leur organisation et leurs techniques de production. L'enquête auprès des entreprises sur laquelle porte l'étude, qui est l'enquête sur les comptes des entreprises (SCI) de l'ISTAT couvrant l'ensemble des entreprises d'au moins de 20 salariés, offre une possibilité de tester l'hypothèse selon laquelle les TIC, qu'il s'agisse du matériel ou du logiciel, peuvent avoir une influence positive sur les performances de la production. L'analyse est réalisée à l'intérieur d'industries définies par la base STAN de l'OCDE, afin de faciliter la comparabilité internationale des résultats empiriques. L'efficience technique de chaque entreprise considérée individuellement est mesurée par analyse de l'enveloppement des données (DEA), qui est une technique non paramétrique bien connue dans le domaine de la recherche opérationnelle. La corrélation entre les TIC et l'efficience technique est examinée au moyen de régressions transversales effectuées sur des données au niveau de l'entreprise dans chaque industrie. La principale conclusion est que l'hypothèse de la corrélation n'est pas rejetée de façon significative dans la majorité des secteurs industriels examinés. De manière générale, les corrélations positives ne sont pas rejetées dans l'ensemble des quatre groupes d'industries définis d'après l'intensité de R-D de la production. Toutefois, l'efficience technique ne semble pas être affectée par les TIC dans une proportion importante des industries à forte intensité de R-D. Ce résultat paradoxal peut s'expliquer en notant que la quasi-totalité des entreprises dans ces industries opèrent déjà à des niveaux relativement élevés d'efficience technique ; il y a peu de marges pour des gains supplémentaires par des accroissements de l'intensité de TIC de la production.

Classification JEL : D2, L2, O4

Mots clés : TIC, Efficience technique, Productivité

\footnotetext{
Istituto di Studi e Analisi Economica, Piazza Indipendenza, 4, 00185 Rome; tel. +39-06-44482300, FAX: +39-06- 44482219; E-mail: c.milana@isae.it.

Istituto Nazionale di Statistica, Via Tuscolana, 1782, 00100 Rome; tel. +39-06-72976165, FAX: +39-06-2970798; E-mail: zeli@istat.it.

Ce papier exprime le point de vue de ses auteurs, et pas forcément celui des institutions associées.
} 
TABLE OF CONTENTS

1. Introduction

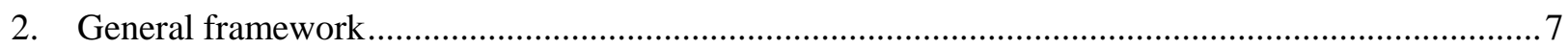

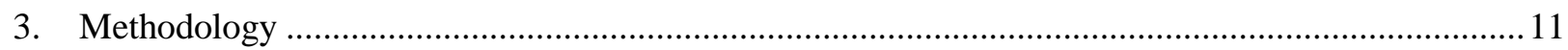

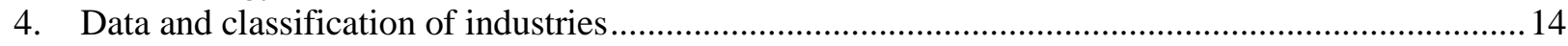

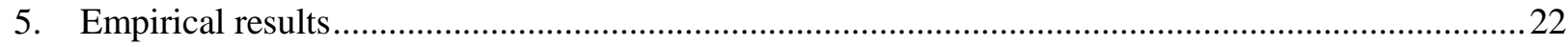

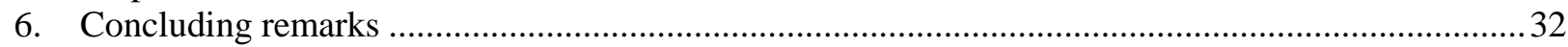

ANNEX 1. ICT IN ITALY: AN INTERNATIONAL PERSPECTIVE ……............................................. 33

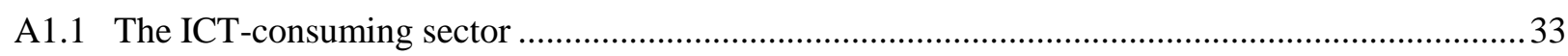

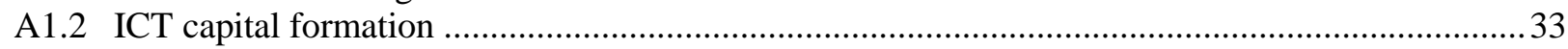

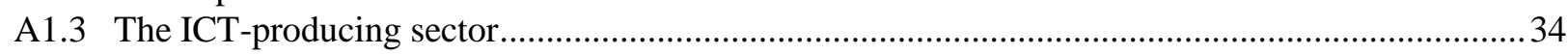

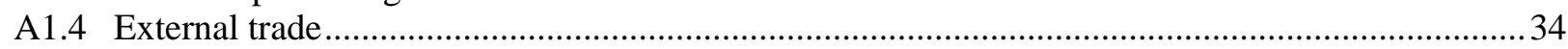

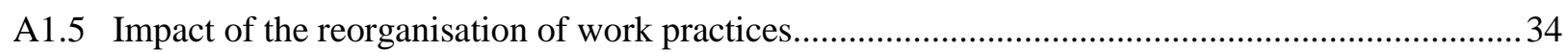

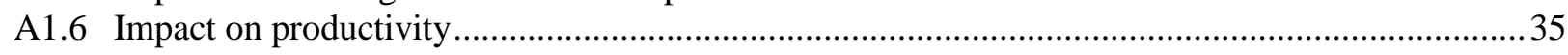

ANNEX 2. ISTAT'S SURVEYS ON ECONOMIC ACCOUNTS OF ENTERPRISES IN ITALY ...........39

ANNEX 3. TECHNICAL EFFICIENCY FROM THE POINT OF VIEW OF LEIBENSTEIN'S THEORY

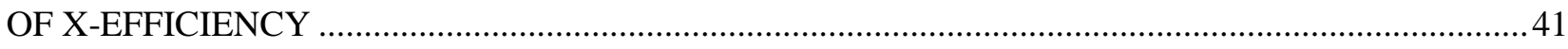

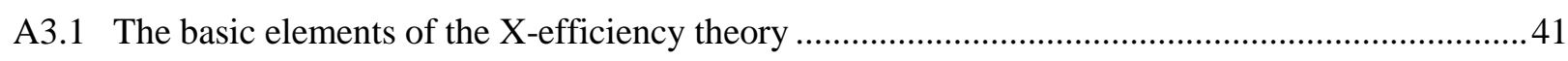

ANNEX 4. MEASURING TECHNICAL EFFICIENCY BY MEANS OF DATA ENVELOPMENT

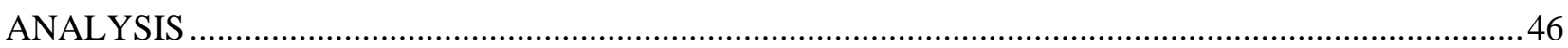

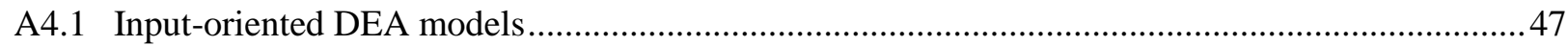

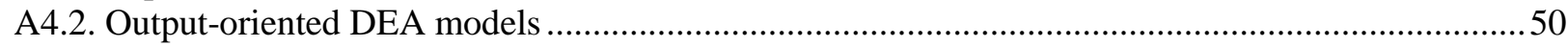

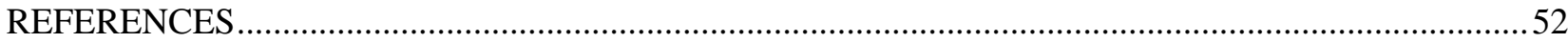




\section{Introduction}

Information and communication technologies (ICTs) are generally defined as manufactured products and services intended to fulfil or enable information processing, communication, use of electronic means to detect, measure or record physical phenomena or to control physical processes ${ }^{1}$. ICTs play a key role in increasing the speed of generation, diffusion and use of new knowledge within and across the boundaries of businesses, markets and nations. ICTs are also intended to help firms acquire the information needed to change the technology of production, optimise the acquisition and use of factor inputs, enhance market distribution of products in a wide range of industries. This even includes industries that are less intensive in the use of skilled labour, employ few researchers, have a low stock of R\&D or few registered patents.

Assessing empirically the role of ICT in production performance is, however, a difficult and complicated task mainly because of the lack of detailed information about investment flows and capital services within the national economic accounts and industrial statistics. Notwithstanding these limitations, a growing number of empirical studies are devoted to the evaluation of various effects of ICT on growth of output, productivity, and the economic behaviour of agents and markets ${ }^{2}$. Many of these studies have been inspired by the conjecture that ICT investments might have raised the speed of technological change in economically advanced areas, shaping a new economy where business cycles are substantially reduced and relatively high rates of economic growth remain sustainable for a long time without inflationary pressures emerging ${ }^{3}$.

The recent and sudden slowdown of the US economy has shown that the warnings against this optimistic view of a new age of growth were well founded. The "overshooting" of ICT investment may in fact have triggered the slowdown. Moreover, the communication technologies themselves enabled expectations and reactions to spread throughout the economy more quickly than in the past. However, whether this turning reflects a short-run phenomenon or is the starting point of a longer period of productivity slowdown, ICT are still expected to improve technical efficiency in production activities. Even during periods of economic slumps, these kinds of technologies are likely to advance rapidly for many years to come. In most economically advanced countries they continue to create new job opportunities and to increase efficiency, as documented by official, private and public statistical sources ${ }^{4}$.

This paper is aimed at finding further evidence, studying the impact of ICTs on technical efficiency in Italy at firm level using survey data covering a wide range of industries. The analysis is conducted using a nonparametric method to measure technical efficiency and econometric regressions to estimate partial correlations between ICT and technical efficiency within each industry, controlling for other "explicative" variables. The basic relevant data are reclassified according to the same industry taxonomy that is adopted

1. See OECD (2000a, p.7) for a similar definition.

2. For surveys of the empirical literature on ICT, productivity and organisational change, see Brynjolfsson and Yang (1996), Brynjolfsson and Hitt (2000), and Hitt and Brynjolfsson (2001). For a survey of the relationships between information technologies, skills, and wages at firm level, see Chennels and van Reenen (2001).

3. See, among others, Greenspan's (2000) famous remarks before the New York Association for Business Economics. Recent studies describing the importance of the ICT for the functioning of the economy include Shapiro and Varian (1999), Brynjolfsson and Kahin (2000), Choi and Whinston (2000), Jorgenson (2001) and OECD (2002).

4. In Italy, for example, a lag in ICT accumulation with respect to the other G7 countries is still visible (see Annex 1). However, the ICT-producing sector is growing rapidly, not only in sales, but also in employment. Over the year 2000, employment increased to 533000 workers, up from 514,000 workers in 1999, corresponding to a rate of change of $3.7 \%$, which is double the rate of employment growth in the overall economy. Another 500000 workers have been employed in ICT-related activities in traditional industries and this area is expected to grow much faster in the coming years than the total number of employees. About $21 \%$ of university graduates in the country are employed in this sector (see, for example, Assinform, 2001 and Federcomin, 2000, 2001). 
by the new OECD STAN database, including mining, manufacturing industries and services. The results can be compared directly with those obtained for other countries by studies that adopt the same methodology and industry classification.

The paper is organised as follows. Section 2 presents the analytical framework derived from the results of previous studies. Section 3 describes the model and the methodology used for the estimation proposed in the present paper. Section 4 offers a description of the database examined and the chosen classification of industries. Section 5 presents the empirical results and their interpretation. Section 6 concludes.

\section{General framework}

The importance of ICT for economic growth has been studied mainly under three different angles ${ }^{5}$ : $(i)$ the increasing weight of ICT industries in the economy, (ii) ICT as a special capital input; (iii) spillovers from ICT usage due to benefits that go beyond those accruing to investors and owners. All these three different angles can be useful to study the direct contribution to output growth deriving from the quantitative increase in ICT usage and the impact on output growth deriving indirectly from effects on technology and productivity.

The effects on productivity can, in turn, be distinguished in improvements of relative technical efficiency of single production units, defined with respect to the best-practice production frontier, and increases in total factor productivity that are induced by technological change and reflected in a shift of the production frontier itself. As the literature on Leibenstein's theory of X-efficiency has shown, these two different effects are generally intertwined, since technological change brings about improvements and changes in the overall organisation of production affecting also relative technical efficiency of individual firms with respect to the industry's best practice (see Annex 3). However, for analytical and empirical purposes we consider these two effects separately.

In order to clarify the results obtained by empirical analyses, recent contributions in the field make a distinction in the effects of ICT on economic growth between direct effects on output growth produced as a factor of production, and the impact on growth through induced changes in technology and relative technical efficiency.

\subsection{Direct effects of ICT on output growth}

The direct effects of ICT on output growth have been studied in a number of recent contributions using the methodology of growth accounting. ICT as a factor of production is considered as a special type of capital with its own characteristics, which are different from those of other types of capital goods. This methodology has been applied in intertemporal comparisons at macro and industry level as well as in international comparisons across industries and countries. At macro level, the results obtained vary according to the period of time considered. Kiley (1999), Council of Economic Advisors (2000; 2001), Whelan (2000), Jorgenson and Stiroh (2000a) and Oliner and Sichel (2000) have found empirical evidence that information technologies contributed very little to US economic growth up to 1995 and that this contribution increased substantially, up to almost one percentage point, in the second half of the 1990s. Oulton (2001) found similar results for the United Kingdom, with the contribution of ICT to output growth rising over time.

5. See, for example, OECD (2000b, pp.49-71). 
Across industries, a wide range of effects can be observed, ranging from the sector producing ICT goods and services, where the highest induced growth rates have been recently reported, to the ICT-using industries, where the gains are more scattered, with many cases of very low output growth. Jorgenson and Stiroh (2000b), Jorgenson (2001) and Stiroh (2001) have obtained empirical evidence at industry level for the US economy ${ }^{6}$.

More uncertain is the assessment of differences of ICT effects across countries. This is mainly due to the fact that the scarce availability of comparable data makes it difficult to perform international comparisons of such effects. At macro level, a series of OECD studies have compared the contribution of ICT to output growth in certain member countries. The methodology used is consistent with that defined in the OECD (2001a) productivity manual, based on growth accounting. Schreyer (2000) used data from the International Data Corporation (1998), a private information source, regarding the productive use of ICT hardware, whereas Colecchia and Schreyer (2001) used a combination of data available in the institutional OECD databases concerning the productive use of ICT hardware and software. The analysis of the contribution of ICT-producing and ICT-using industries to the overall productivity growth of single member countries confirms the key role played by the former group of industries in several countries and the pick-up in productivity growth in the United States during the second half of the 1990s (see Pilat and Lee, 2001, who used the revised OECD STAN database).

Following in the footsteps of previous studies based on growth accounting and using data from WITSA, a consortium of 41 information technologies (IT) industry associations around the world (see WITSA 2000), Daveri $(2000 ; 2001)$ found that in Europe the growth contribution of information technologies during the 1990s was between two-thirds and three-quarters of one percentage point per year in the United Kingdom, the Netherlands, Ireland and Sweden, whereas it was much lower (around 0.3 percentage points per year) in Greece, Italy and Spain, and in between in the rest of Europe. He attributes a non-negligible fraction (varying between 25\% and 90\%) of the gap between the EU countries and the United States to differences in the accumulation of information technologies. Some analysts, however, expect that European economies characterised by intermediate intensity in ICT investments, such as France and Germany, are likely to experience in the near future a period of productivity growth similar to that already seen in the United States. ${ }^{7}$

The impact of ICT on technological change and productivity

All the above-mentioned studies respond to the important question concerning the direct contribution to output growth of ICT capital as a factor of production. Equally important is the question regarding the indirect effects on output growth of capital accumulation and, in particular, of ICT investment on induced productivity gains (approximately summarised by the index of total factor productivity growth). The growth accounting methodology by its very nature misses the point of measuring the role of ICT in increasing productivity through the induced changes in production technology. In fact, this methodology does not fully consider the role of capital as a vehicle of innovation and technological change, determining

6. Positive conclusions have been reached by previous studies for the United States at industry level by Morrison and Berndt (1991), Berndt, Morrison and Rosenblum (1992), Berndt and Morrison (1995), Gill et al. (1997), Beede and Montes (1997).

7. See, for example, Mairesse, Cette and Kocoglu (2000), Baudchon and Brossard (2001), and INSEE (2001). 
productivity growth through the induced implementation of new techniques of production and improvements in productive efficiency. ${ }^{8}$

The debate on the productivity paradox as stated by Solow (1987) ("we can see the computer age everywhere but in the productivity statistics") was originally developed in terms of the effects of a particular type of capital (computers) on technological change and productivity growth rather than in terms of its direct effects on output growth. More than ten years ago the popular view was that information technologies were apparently ineffective with respect to productivity growth (the Solow "productivity paradox" is only the most famous example). The traditional explanations of the "paradox" (measurement difficulties, lags in learning how to use computers productively, low shares in the total capital stock) are now accompanied by the retrospective view that information technologies were not diffused "everywhere" at that time, at least by today's standards ${ }^{9}$. Moreover, economists' expectations about the contribution of ICT to productivity were too high ${ }^{10}$. However, the limits of empirical analyses have left open the debate on the ICT-induced gains in output and productivity growth. In fact, the perceived extent of these gains has changed over time and seems to be different across industries and countries.

Some authors are still doubtful on the empirical relevance of the ICT effects on productivity. Among these, Sichel (1997, p. 76 and pp. 91-93), for example, considers the possibility that information technologies might contribute to gains that are captured by the index of multifactor productivity growth calculated in the context of the neo-classical growth accounting. However, he argues that, in this case, IT would have to exhibit a "supernormal" rate of return, whereas the arguments that he collects "raise questions about how likely this is to have occurred" (p. 93). This conclusion is based on the assumption that the gains in multifactor productivity growth induced by IT are separable from the contribution of other determinants and can always be internalised in the rewards accruing to the same IT. In fact, for various reasons, such gains are not separable and, in general, cannot be internalised specifically in the IT capital rewards.

Assessing the contribution of capital inputs (or determinants) to technological change, as represented by the residual total factor productivity, requires extending the traditional method to a sort of "explanation" of such a residual. This has been recognised by Hulten (2001), who suggested that growth accounting could be jointly employed with other methods, such as that based on econometric techniques, to explain the residual productivity component, thus reducing the "measure of our ignorance". More in line with this kind of question and more closely to the spirit of Solow remarks, other studies have been devoted to assessing the direct influence of ICT on the efficiency or technological advances in production.

Among the most recent analyses, Caselli and Coleman II (2000) show that many low-income countries operate below the world technology frontier and that substantial efficiency gains can be achieved by adopting the technologies already in use in technologically advanced countries. Moreover, Caselli and Coleman II (2001), analysing data on imports of computer equipment, show that computer adoption is associated with high levels of human capital, high investment rates, good property rights protection and manufacturing trade openness vis-à-vis OECD member countries.

8. The neoclassical growth models have been criticised on a similar point from the theoretical literature on endogenous growth. This has pointed to beneficial effects from capital accumulated in external units and in the overall economic system.

9. In consideration of the remarkable post-1995 acceleration in the United States productivity growth, Solow himself has declared his "paradox" obsolete (see Uchitelle, 2000). However, even today, although computers may appear to be everywhere, their use is highly concentrated in services and a few manufacturing industries (see, for example, McGuckin and Stiroh, 1998, Pilat and Lee, 2001, van Ark, 2001, van der Wiel, 2001). At the same time, multifactor productivity growth has actually decelerated in a great part of the United States economy outside durable manufacturing, despite massive investment in computers and related equipment (see Gordon, 2000, p. 72).

10. See, for example, Crafts (2002). 


\subsection{Evidence from micro data}

The collection of micro data at firm or plant-level of various countries is another important starting point for a closer examination of the ICT impact on productivity. To "explain" aggregate productivity growth, a number of empirical studies have examined micro data at the firm- or establishment-level. ${ }^{11}$ The relevance of this type of analysis is confirmed by large and persistent differences in productivity found across firms within the same industry. Aggregate productivity growth can therefore be decomposed in: $(i)$ changes in productivity in individual firms (the so-called "within-firm effect"), and (ii) changes due to compositional effects arising from market reallocation and firm dynamics (expansion and contraction of the market size, expansion and contraction of the firms' market shares, entry and exit of firms, which combined together make up the so-called "between-firm effect").

One example in the direction of greater comparability of productivity and firm dynamics across countries and over time is given by the OECD project on firm-level data, which is itself part of a wider ongoing project of the OECD on growth. The latter is aimed at an exploration of growth patterns across member countries using macro data available at the aggregate and sectoral levels and is being complemented by a collection of micro data at firm level of ten countries (United States, Germany, France, Italy, United Kingdom, Canada, Denmark, Finland, Netherlands and Portugal) ${ }^{12}$. On a basis of a common analytical framework and, where possible, harmonised data, this project has already reached a number of conclusions. A large fraction of aggregate labour productivity growth has been accounted for by restructuring activities within incumbent firms, whereas exit of low productivity firms has boosted the overall labour productivity in mature industries and entry of new units, endowed with a more "efficient" mix of capital and labour and new technologies, has increased the overall labour productivity in industries characterised by rapid technological change, like the ICT-related industries. As for multifactor productivity, a different picture emerges. The within-firm growth makes a relatively smaller contribution than it does to labour productivity. This means that incumbents have raised labour productivity mainly by increasing capital intensity and/or shedding labour rather than improving the overall efficiency in production.

Important results that can be obtained from studies based on micro-data regard the effects from different types of ICT capital goods and services. Lehr and Lichtenberg (1999) and Licht and Moch (1999), for example, find stronger effects of computers on output growth than for other ICT-capital. A further step towards a detailed analysis of ICT effects on productivity can be made by decomposing productivity growth into technological change, represented by changes in the best-practice production frontier, and variations in technical efficiency, given by the distance between the actual production from the production frontier. The former could be empirically analysed at micro level using panel data (cross-section and time series data), while the latter can be analysed also with reference to a certain point of time using crosssection data.

Among cross-sectional analyses, Lichtenberg (1995), Brynjolfsson and Hitt (1995), Black and Lynch (1997), Lehr and Lichtenberg (1999), Dunne, Foster, Haltiwanger and Trotske (2000), and Bresnahan, Brynjolfsson and Hitt (2001) find that in the United States there are strong interactions between ICT and other factors within the firms and these interactions "explain" the major part of productivity growth. Moreover, Greenan and Mairesse (2000), Greenan, Mairesse and Topiol-Bensaid (2001) observe positive correlations of computers, IT and R\&D with productivity, average wages and the share of administrative managers in France.

11. See Bartelsman and Doms (2000), Haltinwanger (2000), and Sanghoon (2001) for recent reviews of these studies.

12. On these firm-level data and their comparability across countries, see Scarpetta, Bartelsman, Portugal, and Schivardi (2001). The collection and examination of these data has been carried out by the OECD in collaboration with a network of researchers from the examined countries. The final report will be completed in 2002. Preliminary results were published in OECD (2001b). 
In the time-series dimension, the relatively scarce data available do not lead to the same robust evidence on the relation between ICT and firms performance as that found by the above-mentioned cross-sectional analyses. While negative results have been obtained by Berndt, Morrison and Rosenblum (1992) for the Unites States, and by Greenan, Mairesse and Topiol-Bensaid (2001) for France, studies such as those made by Brynjolfsson and Hitt (1995) and Siegel (1997), based on very detailed data for United States manufacturing industries, find strong evidence of correlations.

As for Italy, Paganetto, Becchetti and Londono Bedoya (2000) analyse the determinants of IT investment and the impact of the IT component on (labour) productivity and efficiency on a sample of small and medium-sized firms. Using data from the Survey of Manufacturing Firms by Mediocredito Centrale and applying sectoral models of production frontiers, they calculate the distance of each examined firm from this frontier. The main findings are that software investments increase the demand for skilled workers, average labour productivity and proximity to the optimal production frontier. On the other hand, telecommunication investments positively affect the creation of new products and processes but negatively affect average labour productivity.

Another study by Atzeni and Carboni (2001) uses the same data from the Mediocredito Centrale and apply a growth accounting methodology to calculate the total factor productivity residual. This residual is then regressed on a number of variables including an estimate of IT investments and its complements (as, for example, human capital). Addressing the analysis to territorial disparities, they find the impact of ICT on productivity is significant and helps explain the dualism in economic growth between the North and South of Italy.

Bugamelli and Pagano (2001), combining two sources of firm-level data (the Italian company accounts data service by Centrale dei Bilanci and the survey of manufacturing firms by Mediocredito Centrale) and using econometric estimates of a short-run conditional demand function for ICT capital based on production functions, find strong evidence in favour of a complementarity between ICT, human capital and reorganisation of production activities. Finally, Ferri, Galeotti and Ottavio Ricchi (2001) exploit a database appropriately constructed concerning 450 Italian small and medium-sized enterprises and check whether access to Internet and e-commerce has direct effects on firms' sales growth and/or indirect effects on the firms' growth by loosening various constraints. The indirect effects are found to be more pronounced than the direct effects.

\section{Methodology}

A number of alternative methods have been proposed to measure technical efficiency of production units following Farell's (1957) seminal article ${ }^{13}$. Among these, index numbers and the application of stochastic frontier production functions and non-parametric techniques, such as data envelopment analysis (DEA), are the most widely used ${ }^{14}$. Index numbers cannot be implemented without a set of data for prices and quantities. The stochastic frontier approach was independently developed by Aigner, Lovell and Schmidt (1977) and Meeusen and van der Broeck (1977). The main strength of this approach derives from the econometric specification of a model where the production or decision-making units can deviate from the production frontier and this deviation can be decomposed into a stochastic term (noise) and a deterministic inefficiency term. Its main weakness derives from the need of estimating directly a functional form of the

13. Farell (1957), in turn, based his analysis on the pioneering works of Debreu (1951) and Koopmans (1951) in defining a simple measure of technical efficiency of a firm using multiple inputs.

14. For these, and other less popular methods, see the excellent (though not very recent) survey of Lovell (1993) on productive efficiency measurement. 
production frontier that may not be general enough to satisfy all the desirable properties from the points of view of economic theory. ${ }^{15}$

DEA has an overwhelming advantage over the index number and econometric methods in cases when only quantity data are available (see also Diewert and Mendoza, 1995). On the other hand, in its original deterministic version DEA has a greater sensitivity to measurement errors or other statistical noise in the data because it attributes all deviations from the frontier entirely to technical inefficiency. For the purpose of this paper, our analysis is limited to DEA application. Annex 3 provides a more complete description of DEA.

\subsection{Data envelopment analysis: measuring firms' technical efficiency}

The DEA technique applies a separate linear programming problem for each of the firms or production units within an examined industry. Consider $N$ firms in each industry (with $N$ varying across the examined industries). Let the inputs and outputs of the $i$ th firm be respectively represented by the $K$-order column vector $\mathbf{x}_{i}$ and the $M$-order column vector $\mathbf{y}_{i}$. The input and output data for all $N$ firms form the $K \times N$ input matrix $\mathbf{X}$ and the $M \times N$ output matrix $\mathbf{Y}$, respectively.

Assuming the general case, which includes variable returns to scale, the output-oriented measure of the $i$ th firm's technical efficiency is derived from the data envelopment form defined by the following optimisation problem $^{16}$ :

$$
\begin{aligned}
\max _{\phi_{i}, \lambda_{\mathrm{i}}} & \phi_{i} \\
\text { subject to } \quad \mathbf{Y} \lambda_{i}-\phi_{i} \mathbf{y}_{i} & \geq \mathbf{0}_{M} \\
\mathbf{x}_{i}-\mathbf{X} \lambda_{i} & \geq \mathbf{0}_{K} \\
\mathbf{N 1} \cdot \boldsymbol{\lambda}_{i} & =1 \\
\lambda_{i} & \geq \mathbf{0}_{N}
\end{aligned}
$$

where $1 \leq \phi_{i}<\infty$, with $\phi_{i}$ being a scalar, $\lambda_{i}$ is an $N$-order column vector of constants, $\mathbf{N} 1$ is an $N$-order column vector of ones. The convexity constraint $\left(\mathbf{N} 1^{\prime} \cdot \lambda_{i}=1\right)$ ensures that an inefficient production unit is only "benchmarked" against production units of a similar size (in the case of constant returns to scale, this constraint is not imposed, the $\lambda_{i}$ weights sum up to a value different from one and the benchmarking may be made against production units that are substantially larger or smaller than the examined $i$ th production unit). The value $\left(\phi_{i}-1\right)$ is the proportional increase in output(s) that could be obtained by the $i$ th production unit with the input quantities held constant. The output-oriented measure of technical efficiency $\left(\mathrm{TE}_{i}\right)$ of the $i$ th production unit is given by:

15. For a similar critical view of the stochastic frontier approach, see Balk, de Boer and Greve (2001) who point out the relative convenience of inexpensive analytical techniques, such as DEA, resting on a minimal number of assumptions. Several other studies compare stochastic approaches and DEA, for example Cummins and Zi (1998) and Sharma, Leung and Zaleski (1997).

16. See Annex 4 for the derivation of this optimization problem, which corresponds to the envelopment form (A4.6). 


$$
\mathrm{TE}_{i}=1 / \phi_{i}
$$

$\mathrm{TE}_{i}$ varies between zero and one $\left(0<\mathrm{TE}_{i} \leq 1\right.$, where $\mathrm{TE}_{i}=1$ means that the $i$ th production unit is fully efficient and operates on the best-practice frontier).

\subsection{Cross-sectional regressions: “explaining” firms' technical efficiency}

Correlation of the ICT capital stock and the degree of technical efficiency of production across production units can be tested by regressing the respective degree of technical efficiency $\operatorname{TE}_{i}(i=1, \ldots, N)$ on the ICT capital inputs and a set of other relevant "explaining" variables. For each industry, we specify and estimate the following cross-sectional regression expressed in matrix notation (for simplicity of notation, the industry index is not shown $)^{17}$

$$
\begin{aligned}
\text { TE } & =\beta_{0}+\beta_{1} \text { SOFT }+\beta_{2} \text { HDTC }+\beta_{3} \text { R\&D }+\beta_{4} \text { CLUOP }+\beta_{5} \text { CLUID }+\beta_{6} \text { SIZE }+\beta_{7} \text { RIP } \\
& +\beta_{8} \text { K/L }+\beta_{9} \text { FATTAD }+\beta_{10} \text { DEB_K }+\beta_{11} \text { SKILL }+\varepsilon
\end{aligned}
$$

where TE: firms' relative levels of technical efficiency.

SOFT: ratio between stock of software and total tangible and intangible assets.

HDTC: ratio between stock of ICT equipment and total tangible and intangible assets.

R\&D: $\quad$ ratio between stock of $R \& D$ expenses at constant prices and turnover.

CLUOP: ratio between "blue-collar" labour costs and number of employees within the firm.

CLUID: ratio between "white-collar" labour costs and number of "white-collar" employees.

SIZE: dummy variable for small \& medium-sized enterprises (employing from 20 to 99 workers) and large enterprises (employing over 99 workers).

RIP: dummy variable for the firm's territorial location (Central-North and Southern Italy).

$\mathbf{K} / \mathbf{L}$ : ratio between tangible plus intangible assets and number of employees.

FATTAD: turnover per worker employed.

DEB_K: ratio between total debt and capital.

SKILL: ratio between white collar and total employees.

$\varepsilon: \quad$ stochastic errors (normally distributed).

17. The regression could give results that are affected by possible omitted variables. For this reason, we have tried to include as many relevant variables as possible, compatible with the information obtained in the available dataset. 


\subsection{Software used for measurement and estimations}

The computer programme used for the DEA estimation is DEAP Version 2.1, which is a programme developed in FORTRAN (Lahey F77LEM/32) by Tim Coelli to be run under MS-DOS 5.0 or higher versions for IBM-compatible PCs (see Coelli, 1996 for the user's guide) ${ }^{18}$. The regression estimations have been made using SAS package. This software yields rich diagnostic indicators and is particularly useful to process a large number of data.

\section{Data and classification of industries}

Micro data at firm level are regularly collected for Italy by ISTAT, the Italian National Statistical Institute and are organised within the European classification of industries. We have reorganised these data under the same industry classification used by the OECD studies to facilitate comparability of the results with those obtained by other studies for other non-European countries. Detailed description of these data and the industry classification is given in the following two subsections.

\subsection{Database and variables}

The production unit data are taken from ISTAT's (the Italian National Statistical Institute) annual survey on economic accounts of the enterprises operating in Italy, which is constructed on the basis of firm-level annual surveys, conducted according to the principles of Directive IV of the EEC on the firms with 20 or more employees. The data are described in ISTAT (1998). Although methodologies are used to integrate the survey data with estimates for non-responding firms, we use here only data that are actually collected. The year taken into consideration is 1997, which is the last year with a survey of firms belonging to this class of employment level (Annex 2 gives some information about the availability of ICT data in the ISTAT annual surveys in recent years).

The number of respondent firms turned out to be over 20000 , operating in all manufacturing and service industries, except credit, insurance and public services. The rate of response is less than $50 \%$, but the turnover and value added of the respondent firms account for about $70 \%$ of the corresponding variables of all firms with at least 20 employees, whereas employment amounts to a share of about $65 \%$.

The survey provides all the information needed to construct the "explanatory" variables listed in the regression model (3). It collects all book values from the balance sheet (assets and liabilities) and profits and loss accounts. Moreover, data concerning employment, investments, personnel costs and regional information are also collected.

At the ith firm level, we focus our investigation on the variables concerning output and inputs of production as follows:

1. Output $\left(y_{i}\right)$, approximated by turnover of the firm.

2. Labour inputs $\left(x_{1 i}\right)$, represented by the total number of persons employed by the firm.

18. A copy of DEAP Ver. 2.1 can be downloaded from the Internet Web site of the Centre for Efficiency and Productivity Analysis, University of New England, Department of Econometrics, NSW, Australia, at the URL

http://www.une.edu.au/econometrics/cepa2.htm\#software (see Hollinngsworth, 1999 for a comparison of alternative computer programs performing DEA). 
3. Intermediate inputs $\left(x_{2 i}\right)$, represented by the sum of purchase costs for raw materials, manufactured goods, energy, power and services.

4. Capital inputs $\left(x_{3 i}\right)$, represented by book values of all tangible and intangible assets of the firm (including ICT inputs).

\subsection{Classification of industries}

According to its main economic activity, each firm is originally associated with an industry defined within the ATECO classification, which is a disaggregated version of the EUROSTAT NACE, Rev. 1 industry classification. In order to facilitate a high comparability at the international level of our results, industries are redefined according to the industry classification adopted in the input-output tables of the renewed OECD STAN industrial statistical system. ${ }^{19}$ This classification is designed to take into account the technology intensity and/or trade sensitivity of sectoral production activities and was initially organised by making reference to the second revision of the International Standard Industrial Classification (ISIC, rev. 2) established by the United Nations Statistical Office (1968). ISIC, Rev. 2 is now being replaced by ISIC, Rev. 3 established by the United Nations Statistical Office (1990) and the OECD input-output industry classification is being redefined by making direct reference to this last version of ISIC. ${ }^{20}$ However, the original input-output classification turns out to be compatible also with ISIC, Rev. 3, so that only minor changes where made in its updating. Moreover, since EUROSTAT NACE, Rev.1 is fully compatible with ISIC, Rev. 3, no particular problem arises in bringing the ISTAT SCI survey data under the chosen industry classification. ${ }^{21}$ The resulting list of industries is given in Table 1.

The ISTAT SCI survey allows us to analyse firms within the industries numbered from 2 to 30 , from 32 to 34, and from 36 to 38 in Table 1. A few industries like Agriculture, forestry and fishery, Finance and insurance, and certain economic activities such as Public Administration and Defence, International services are excluded from the analysis.

For the purpose of our analysis a further distinction between ICT-producing and ICT-consuming sectors is particularly useful. The OECD Secretariat has recently identified the former sector under the guidance of the Working Party on Indicators for the Information Society (WPIIS). The agreed definition of the ICT sector was made according to the following principles: for manufacturing industries belonging to this sector, their products "must be intended to fulfil the function of information processing and communication including transmission and display" or they "must use electronic processing to detect, measure and/or record physical phenomena or to control a physical process". For services belonging to the same sector, their products "must be intended to enable the function of information processing and communication by electronic means" ${ }^{\prime 2}$. The adoption of these principles led to a definition of the ICT-producing sector in terms of industrial classes of ISIC, Rev. 3 at 4-digit level of disaggregation (see OECD, 2000a, p. 7).

19. The new OECD STAN classification has been defined in accordance with the latest definitions outlined in the updated version of the System of National Accounts issued in 1993 under the auspices of the Intersecretariat Working Group on National Accounts, which consists of officials from the OECD, the International Monetary Fund, the United Nations Statistical Division, the World Bank and the Commission of the European Communities. On-line information concerning the new OECD STAN database is available at: http://www1.oecd.org/dsti/sti/stat-ana/stats/new_stan.htm .

20. On-line access to all economic classifications of the UN Statistical Division is available through the Internet URL http://www.un.org/Depts/unsd/class/prodserv.htm. These classifications can be directly consulted at: http://esa.un.org/unsd/cr/registry/regcst.asp .

21. For a correspondence between the EUROSTAT NACE, Rev. 1 and the OECD industry classification, see Milana (1999) and John Haveman's homepage: http://www.eiit.org/Trade.Resources/TradeConcordances.html

22. See OECD (2000a, p.7). 
Table 2a shows the list of these industrial classes and their correspondence with the new OECD STAN industry classification. A more approximate definition of the ICT-producing sector has been given by the OECD Secretariat on the bases of the industrial classes of ISIC, Rev. 3 at 2-digit level of disaggregation (see OECD, 2001d, p. 24). This definition fits completely with the new OECD STAN industry classification, as shown in Table $2 b^{23}$.

The ICT-consuming activities are defined residually by excluding the ICT-producing activities from the whole set of industries in the economy. This is done for practical reasons only, following a tradition already established in OECD studies in this field (see, for example, Pilat and Lee, 2001) ${ }^{24}$.

The manufacturing sector appears to be more disaggregated than the agriculture, mining and service sectors. Industries 3 to 24 , which make up the manufacturing sector in this classification, have been regrouped into four broad classes of industries in OECD, (1996, Vol. 2, pp. 61-62): one is based on technology, one on wage levels, one on production orientation and one on skill levels. For the purposes of our analysis, the technology-based criterion is of particular importance. This grouping of industries has been redefined by the OECD (see, for example, Hatzichronoglou, 1997). More recently, the reorganisation of the OECD STAN database has made it possible to include service industries. Moreover, the abovementioned technology-based industry taxonomy has been termed as a "knowledge-based" grouping of industries, since it follows the R\&D intensity criterion (see Webb, 2001).

23. This approximate definition of the ICT-producing sector does not include such ICT-producing activities as "Insulated wire and cable" (3130), "Wholesale of machinery, equipment and supplies" (5150), "Renting of office machinery and equipment (including computers)" (7123), whereas it includes non-ICT producing activities as "Medical and surgical equipment and orthopaedic appliances" (3311), "Optical instruments and photographic equipment" (3320), "Watches and clocks" (3330), "National post activities" (6411), "Courier activities other than national post activities" (6412) (ISIC, Rev. 3 code numbers are shown in parenthesis).

24. A different definition of the ICT-producing industries and ICT-consuming industries, with an overlapping between these two groups of industries, is adopted by van Ark (2001) and the ICT database of the Groningen Growth and Development Centre (which is described in the Web page at the Internet URL http://www.eco.rug.nl/GGDC/ictdatabase.html ). 
Table 1. Industry classification in the new OECD input-output database

\begin{tabular}{|c|c|c|c|}
\hline \multicolumn{2}{|r|}{ Industry } & ISIC, Rev. 3 & $\begin{array}{l}\text { Approximate } \\
\text { ISIC, Rev. } 2\end{array}$ \\
\hline 1 & Agriculture, forestry and fishery & $01+02+05$ & 01 \\
\hline 2 & Mining and quarrying & $10+11+12+13+14$ & 02 \\
\hline 3 & Food, beverages and tobacco & $15+16$ & 31 \\
\hline 4 & Textiles, apparel and leather & $17+18+19$ & 32 \\
\hline 5 & Wood, wood products and cork & 20 & 33 \\
\hline 6 & Pulp, paper, paper products and printing & $21+22$ & 34 \\
\hline 7 & Petroleum, coal products and nuclear fuel & 23 & $353+354$ \\
\hline 8 & Chemicals, excluding pharmaceuticals & 24 ex 2423 & $351+352-3522$ \\
\hline 9 & Pharmaceuticals & 2423 & 3522 \\
\hline 10 & Rubber and plastics products & 25 & $355+356$ \\
\hline 11 & Other non-metallic mineral products & 26 & 36 \\
\hline 12 & Iron and steel & $271+2731$ & 371 \\
\hline 13 & Non-ferrous metals & $272+2732$ & 372 \\
\hline 14 & Fabricated metal products & 28 & 381 \\
\hline 15 & Machinery and equipment n.e.c. & 29 & $382-3825$ \\
\hline 16 & Office, accounting and computing machinery & 30 & 3825 \\
\hline 17 & Electrical machinery and apparatus n.e.c. & 31 & $383-3832$ \\
\hline 18 & Radio, TV and communication equipment & 32 & 3832 \\
\hline 19 & Medical, precision and optical instruments & 33 & 385 \\
\hline 20 & Motor vehicles \& trailers & 34 & 3843 \\
\hline 21 & Shipbuilding and repairing & 351 & 3841 \\
\hline 22 & Aircraft and spacecraft & 353 & 3845 \\
\hline 23 & Railroad equipment and transport equip. n.e.c. & $352+359$ & $3842+3844+3849$ \\
\hline 24 & Other manufacturing, recycling & $36+37$ & 39 \\
\hline 25 & Electricity, gas and water supply & $40+41$ & 4 \\
\hline 26 & Construction & 45 & 5 \\
\hline 27 & Wholesale and retail trade, repairs & $50+51+52$ & $61+62$ \\
\hline 28 & Hotels and restaurants & 55 & 63 \\
\hline 29 & Transport and storage & $60+61+62+63$ & 71 \\
\hline 30 & Post and telecommunications & 64 & 72 \\
\hline 31 & Finance, insurance & $65+66+67$ & $81+82$ \\
\hline 32 & Real estate, renting and other business services & $70+71+74$ & $83-8323-8324$ \\
\hline 33 & Computer services and related activities & 72 & 8323 \\
\hline 34 & Research and development & 73 & $8324+932$ \\
\hline 35 & Public administration & 75 & 91 \\
\hline 36 & Education & 80 & 931 \\
\hline 37 & Health and social work & 85 & $933+934$ \\
\hline 38 & Other community, social and personal serv. & $90+91+92+93+95+99$ & $92+935+939+94+95+96$ \\
\hline
\end{tabular}
Source: OECD (2001c, p.4). 
Table 2a. OECD definition of the ICT-producing sector, based on the 4-digit level of ISIC, Rev.3 classification

\begin{tabular}{|c|c|c|}
\hline Industry description & ISIC, Rev. 3 & $\begin{array}{l}\text { OECD industry } \\
\text { classification No. } \\
\text { (see Table 1) }\end{array}$ \\
\hline \multicolumn{3}{|l|}{ Manufacturing } \\
\hline Office, accounting and computing machinery & 3000 & 16 \\
\hline Insulated wire and cable & 3130 & $17(\mathrm{p})$ \\
\hline \multirow{2}{*}{$\begin{array}{l}\text { Electronic valves and tubes and other electronic components } \\
\text { Television and radio transmitters and apparatus for line } \\
\text { telephony and line telegraphy }\end{array}$} & 3210 & $18(\mathrm{p})$ \\
\hline & 3220 & $18(p)$ \\
\hline $\begin{array}{l}\text { Television and radio receivers, sound or video recording or } \\
\text { reproducing apparatus, and associated goods }\end{array}$ & 3230 & $18(p)$ \\
\hline $\begin{array}{l}\text { Instruments and appliances for measuring, checking, testing, } \\
\text { navigating and other purposes, except industrial process control } \\
\text { equipment }\end{array}$ & 3312 & $19(p)$ \\
\hline Industrial process control equipment & 3313 & $19(\mathrm{p})$ \\
\hline \multicolumn{3}{|l|}{ Services - goods related } \\
\hline \multirow{2}{*}{$\begin{array}{l}\text { Wholesale of machinery, equipment and supplies* } \\
\text { Renting of office machinery and equipment (including } \\
\text { computers) }\end{array}$} & 5150 & $27(p)$ \\
\hline & 7123 & $32(p)$ \\
\hline \multicolumn{3}{|l|}{ Services - intangible } \\
\hline Telecommunications & 6420 & $30(p)$ \\
\hline Computer and related activities & 7200 & 33 \\
\hline
\end{tabular}

Source: OECD (2000a, p. 7), Pilat and Lee (2001, p. 5).

*Where possible, OECD member countries were asked to limit this class to include only wholesaling of ICT goods considered in the Manufacturing component.

(p) Part of industry production.

Table 2b. OECD (approximate) definition of the ICT-producing sector, based on the 2-digit level of ISIC, Rev. 3 classification

\begin{tabular}{|lcc|}
\hline \multicolumn{1}{|c|}{ Industry description } & ISIC, Rev. 3 & $\begin{array}{c}\text { OECD industry } \\
\text { classification no. } \\
\text { (see Table 1) }\end{array}$ \\
\hline Manufacturing & & 16 \\
Office, accounting and computing machinery & 30 & 18 \\
Radio, TV and communication equipment and apparatus & 32 & 19 \\
Medical, precision and optical instruments & 33 & 30 \\
Services & & 33 \\
Post and telecommunications & 64 & 72 \\
Computer and related activities & & \\
\hline
\end{tabular}

Source: OECD (2001d, p. 24).

Table 3 presents the OECD ranking of industries based on the relative intensity of R\&D in production. The first and second columns give the indicator of relative R\&D intensity (RI) for Italy in 1996 and the G7 countries in 1997. This indicator is given by a ratio between the R\&D stock per unit of the industry gross output and the total R\&D stock in all industries per unit of total output. The ranking of industries is constructed by making reference to a threshold level of RI for the 6-7 countries. High R\&D intensity industries are those exhibiting RI greater than 4. Medium-high R\&D intensity industries are those with RI greater than 1 and less or equal to 4 . Medium-low R\&D intensity industries are those with RI greater than or equal to 0.5 and less than or equal to 1 . Low R\&D intensity industries are those with RI less than 0.5 . 
The third and fourth columns of Table 3 show the frequency distribution of firms by industry in number of units and in percent of the total number of respondent firms to the ISTAT SCI survey. It can be noted that the distribution of firms by industry reflects the specialisation model of the Italian productive system, which is mainly concentrated in low and medium-low R\&D intensity productions, but also in part the nature of the typical firm organisation of each industry. In particular, it can be noted that high R\&D intensive industries are represented by only $3.0 \%$ of total firms in the survey. The highest frequencies can be observed in Wholesale and retail trade, with a share of $13.5 \%$ of the total of firms considered in the survey, Textiles, apparel and leather, with a share of $10.1 \%$, and Non-electrical machinery, with a share of $7.4 \%$. Other relevant shares can be observed in Construction, with $8.1 \%$ of total firms, and Real estate and business services, with $7.2 \%$ of total firms.

Another criterion for grouping of industries that may be important for the purpose of our analysis is that based on relative ICT intensity of use in production activities. Using an indicator similar to RI, we define the indicator of relative ICT intensity (TI) in production. ${ }^{25}$ This indicator is given by a ratio between the ICT capital stock per unit of the industry gross output and the total ICT stock in all industries per unit of total output. The ranking of industries is constructed by making reference to threshold levels of TI. To derive a distribution of industries between the groups considered, we arbitrarily set the threshold levels of TI. High ICT intensity industries are those that exhibit TI greater than 2. Medium-high ICT intensity industries are those with TI greater than 1 and less or equal to 2 . Medium-low intensity industries are those with TI greater than or equal to 0.5 and less than or equal to 1 . Low ICT intensity industries are those with TI less than 0.5 .

Table 4 presents the OECD ranking of industries based on the TI indicator that is constructed using ISTAT' SCI data for the Italian firms operating in 1997. For a comparison with available comparable information for other countries, we include also the values of the TI indicator that we have constructed on the data presented by van Ark (2001) for The Netherlands and indications of ICT intensive industries in the United States that we have derived from other sources.

Figure 1 shows the ratio between the average ICT capital stock and the average total of fixed capital stock and software stock by industry and the average ratio between the ICT capital stock and the total of fixed capital stock and software stock at firm level. The ICT-capital ratios follow the pattern of the relative ICTintensity grouping of industries, with few exceptions. It can also be noted that, in general, the ratio between the average values of ICT and total capital stock at industry level is much higher than the average of ratios calculated at firm level. This result can be explained by the fact that large firms can exploit ICT better than small firms also with respect to other types of capital goods.

25. Data on ICT intensity are not available for many countries. The ranking in this paper is primarily based on results for Italy. 
Table 3. Ranking of industries by relative $R \& D$ intensity (RI)* and frequency distribution of respondent firms

\begin{tabular}{|c|c|c|c|c|}
\hline \multirow[t]{2}{*}{ Industry } & \multicolumn{2}{|c|}{ Relative R\&D intensity (RI) } & \multicolumn{2}{|c|}{$\begin{array}{l}\text { Frequency distribution of firms in the } \\
\text { ISTAT SCl survey, } \\
\text { Italy }\end{array}$} \\
\hline & Italy 1996 & G7 1997 & No. of firms & Percent \\
\hline High R\&D intensity industries $(R I>4)$ & & & 776 & 2.9 \\
\hline Aircraft and spacecraft & 34.44 & 10.74 & 19 & 0.1 \\
\hline Pharmaceuticals & 13.59 & 9.81 & 148 & 0.6 \\
\hline Office accounting and computing machines & 15.26 & 9.48 & 45 & 0.2 \\
\hline Radio, television and communication equipment & 34.54 & 6.91 & 219 & 0.8 \\
\hline Medical, precision and optical instruments & 3.18 & 6.65 & 345 & 1.3 \\
\hline Medium-High R\&D intensity industries $(4 \geq R \mid>1)$ & & & 4,210 & 15.6 \\
\hline Research and development & n.a. & 3.94 & 34 & 0.1 \\
\hline Electrical machinery and apparatus n.e.c. & 2.47 & 3.42 & 833 & 3.1 \\
\hline Motor vehicles, trailers and semi-trailers & 7.22 & 3.11 & 343 & 1.3 \\
\hline Railroad equip. and transport equipment n.e.c. & 3.97 & 2.73 & 93 & 0.3 \\
\hline Chemicals, excluding pharmaceuticals & 2.10 & 2.43 & 482 & 1.8 \\
\hline Computer activities and related services & n.a. & 1.75 & 427 & 1.6 \\
\hline Non-electrical machinery and equipment n.e.c. & 1.20 & 1.63 & 1,998 & 7.4 \\
\hline Medium-low R\&D intensity industries $(1 \geq R I \geq 0.5)$ & & & 4,544 & 16.2 \\
\hline Other non-metallic mineral products & 0.17 & 0.80 & 945 & 3.5 \\
\hline Rubber and plastics products & 1.21 & 0.75 & 910 & 3.4 \\
\hline Coke, refined petroleum and nuclear products & 0.41 & 0.71 & 66 & 0.2 \\
\hline Post and communications & 1.15 & 0.70 & 27 & 0.1 \\
\hline Iron and steel & $0.48^{\star *}$ & $0.63^{* *}$ & 564 & 2.1 \\
\hline Non-ferrous metals & & & 174 & 0.6 \\
\hline Shipbuilding and repairing & 4.66 & 0.62 & 65 & 0.2 \\
\hline Fabricated metal products & 0.64 & 0.55 & 1,793 & 6.6 \\
\hline Education & - & - & 88 & 0.3 \\
\hline Low $R \& D$ intensity industries $(0.5>R I)$ & & & 17,480 & 64.7 \\
\hline Mining and quarrying & - & - & 120 & 0.4 \\
\hline Other manufacturing, recycling & 0.21 & 0.33 & 373 & 1.4 \\
\hline Pulp, paper, paper products and printing & 0.05 & 0.32 & 912 & 3.4 \\
\hline Food products, beverages and tobacco & 0.24 & 0.31 & 1,046 & 3.9 \\
\hline Textile, textile products, leather and footwear & 0.06 & 0.28 & 2,736 & 10.1 \\
\hline Wood, wood products and cork & 0.14 & 0.24 & 1,250 & 4.6 \\
\hline Wholesale and retail trade, repairs & 0.02 & 0.24 & 3,650 & 13.5 \\
\hline Electricity, gas and water supply & 0.92 & 0.23 & 152 & 0.6 \\
\hline Real estate, renting, other business services n.e.c. & 0.10 & 0.10 & 1,489 & 5.5 \\
\hline Construction & 0.03 & 0.09 & 2,196 & 8.1 \\
\hline Finance, insurance & 0.00 & 0.07 & - & - \\
\hline Transport and storage & 0.03 & 0.06 & 1,476 & 5.5 \\
\hline Hotels and restaurants & 0.00 & 0.04 & 890 & 3.3 \\
\hline Health and social works & - & - & 657 & 2.4 \\
\hline Other community, social and personal services & $0.01^{\circ}$ & 0.00 & 445 & 1.7 \\
\hline Total & 1.00 & 1.00 & 27,010 & 100.0 \\
\hline Memorandum: Absolute total R\&D intensity & $(0.36)$ & $(1.17)$ & & \\
\hline
\end{tabular}

Source: Webb (2001) for the relative $R \& D$ intensity indicators shown in the two left-hand columns.

${ }^{*}$ Relative $R \& D$ intensity (RI) is defined as the ratio between the R\&D stock per unit of the industry gross output and the total R\&D stock in all industries per unit of total output.

**Including Non-ferrous metals; including Education and Health and social works. 
DSTI/DOC(2002)13

Table 4. Ranking of industries by relative ICT intensity (TI)*

\begin{tabular}{|c|c|c|c|c|c|}
\hline \multirow[t]{3}{*}{ Industry } & \multicolumn{2}{|c|}{ Relative ICT intensity (TI) } & \multirow{2}{*}{\multicolumn{3}{|c|}{$\begin{array}{c}\text { Major ICT consuming industries } \\
\text { United States }\end{array}$}} \\
\hline & \multirow[b]{2}{*}{$\begin{array}{c}\text { Italy } \\
\text { (our calculations) } \\
\text { on data from } \\
\text { ISTAT's SCI } \\
\text { survey } 1997\end{array}$} & \multirow[b]{2}{*}{$\begin{array}{c}\text { Netherlands } \\
\text { (our calculations) } \\
\text { on data from } \\
\text { Van Ark, } 2001, \\
\text { p. } 37\end{array}$} & & & \\
\hline & & & $\begin{array}{l}\text { McGuckin \& } \\
\text { Stiroh } \\
(1998,2001)\end{array}$ & $\begin{array}{c}\text { NSF } \\
(2000, \\
\text { Appendix } \\
\text { Table 9-3) }\end{array}$ & $\begin{array}{c}\text { US Dept. } \\
\text { of } \\
\text { Commerce } \\
\text { (1999) }\end{array}$ \\
\hline \multicolumn{6}{|l|}{ High ICT intensity industries $(\mathrm{Tl}>2)$} \\
\hline Finance, insurance & - & $7.33,2.00$ & $x$ & $x$ & \\
\hline Research and development & 6.30 & 1.33 & & $x$ & \\
\hline Office, accounting and computing machinery & 4.88 & 1.00 & $\mathrm{x}$ & $x$ & \\
\hline Post and telecommunications & 2.23 & 2.00 & & $x$ & $x$ \\
\hline Computer and related activities & 2.18 & 4.33 & & $x$ & \\
\hline \multicolumn{6}{|l|}{ Medium-high ICT intensity industries $(2 \geq \mathrm{TI}>1)$} \\
\hline Education & 1.79 & - & & & \\
\hline Radio, TV and communication equipment & 1.43 & 1.67 & $x$ & $x$ & $x$ \\
\hline Aircraft and spacecraft & 1.38 & - & & & \\
\hline Transport and storage & 1.12 & - & & & \\
\hline Real estate, renting of machin., other business serv. & 1.10 & 1.67 & $x$ & $x$ & $x$ \\
\hline \multicolumn{6}{|l|}{ Medium-low ICT intensity industries $(1 \geq T I \geq 0.5)$} \\
\hline Railroad equipment and transport equipment n.e.c. & 0.70 & - & & & \\
\hline Other community, social and personal services & 0.64 & - & & & \\
\hline Chemicals, excluding Pharmaceuticals & 0.54 & 1.17 & & $x$ & $x$ \\
\hline Machinery and equipment n.e.c. & 0.52 & - & & & \\
\hline Wood, wood products and cork & 0.52 & - & & & \\
\hline Fabricated metal products, ex. Machinery and equip. & 0.52 & - & & & \\
\hline \multicolumn{6}{|l|}{ Low ICT intensity industries $(0.5>\mathrm{TI})$} \\
\hline Pulp, paper, paper products and printing & 0.49 & 1.50 & $x$ & & \\
\hline Other non-metallic mineral products & 0.46 & - & & & \\
\hline Health and social work & 0.41 & - & & & $x$ \\
\hline Electricity, gas and water supply & 0.39 & - & & & $x$ \\
\hline Other manufacturing, recycling & 0.38 & - & & & \\
\hline Rubber and plastic products & 0.37 & - & & & \\
\hline Medical, precision and optical instruments & 0.36 & 0.67 & $x$ & $x$ & $x$ \\
\hline Mining and quarrying & 0.36 & - & & & \\
\hline Electrical machinery and apparatus n.e.c. & 0.36 & 0.50 & $x$ & $x$ & $x$ \\
\hline Textiles, apparel and leather & 0.35 & - & & & \\
\hline Construction & 0.34 & - & & & \\
\hline Shipbuilding and repairing & 0.33 & - & & & \\
\hline Hotels and restaurants & 0.31 & - & & & \\
\hline Iron and steel & 0.26 & - & & & \\
\hline Food, beverages and tobacco & 0.26 & - & & & \\
\hline Petroleum, coal products and nuclear fuel & 0.25 & - & & & $x$ \\
\hline Motor vehicles \& trailers & 0.23 & - & & & \\
\hline Wholesale and retail trade, repairs & 0.23 & 1.17 & $x$ & $x$ & $x$ \\
\hline Non-ferrous metals & 0.15 & - & & & \\
\hline Pharmaceuticals & 0.12 & - & & & \\
\hline
\end{tabular}

${ }^{*}$ Relative ICT intensity (TI) is defined as the ratio between the ICT capital stock per unit of the industry gross output and the total ICT stock in all industries per unit of total output. 
Figure 1. ICT/(tangible capital \& software) by industry in Italy, 1997 (in \%)
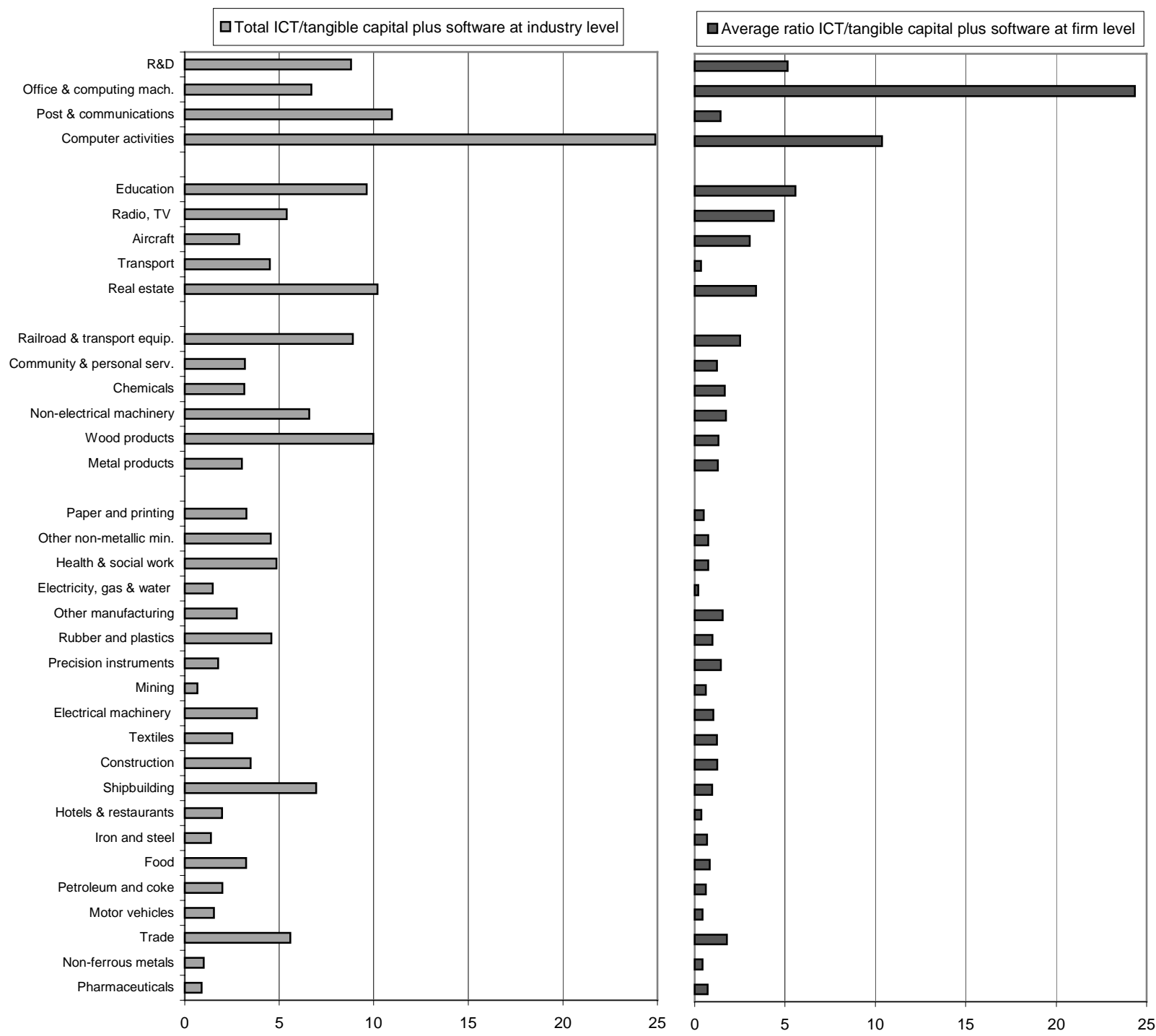

\section{Empirical results}

The methodology described in Section 3 has been applied to the available data of the ISTAT SCI survey on Italian firms with at least 20 employees operating in the year 1997. The empirical exercise has produced indexes of the firms' technical efficiency relative to the production frontier using DEA and estimates of parameters of ICT and other variables in a relation "explaining" technical efficiency, using cross-sectional regressions.

\subsection{DEA results on firms' technical efficiency}

Table 5 presents summary results of DEA by industry and groups of industries. Mean values, standard deviations from the mean, and coefficients of variation of the firms' technical efficiency are shown along with the respective population of respondent firms within the survey. The mean value of TE is quite high for manufacturing industries and relatively low in services, whereas the coefficient of variation is quite low in manufacturing industries and very high in several services reflecting different degrees of concentration 
of the firms near the efficient frontier. This evidence depends partly also on problems of measurement of outputs and inputs in service activities. Services are often not well defined and the "intangibleness" of the respective products make their quality very difficult to be evaluated, thus allowing inefficient firms to continue production activities and operate in the market for a long time.

High and medium-high R\&D intensity industries are those that exhibit high degrees of relative technical efficiency with coefficients of variation lower than those observed in the other groups of industries. Particularly high is relative technical efficiency and particularly low the coefficient of variation in aircraft and spacecraft, railroad and other transport equipment, motor vehicles, chemicals, pharmaceuticals, office accounting and computing machines, where in some cases the limited number of firms contribute substantially to explain this empirical evidence. Relatively low, however, appears the mean value of relative $\mathrm{R} \& \mathrm{D}$ intensity in computer activities and related services with a coefficient of variation relatively high, which reflects the significant heterogeneity of activities and firms in this field.

Medium-low and low R\&D intensity industries show some variability in technical efficiency and dispersion of firms with respect to the most efficient units. Relatively efficient are the firms in post and communications, shipbuilding and repairing, wood products, rubber and plastic products, other nonmetallic mineral products, where the dispersion of firms appears to be relatively low. Much less efficient are, on average, firms operating in other community, social and personal services, construction, transport and storage, wholesale and retail trade, fabricated metal products, where the mean value of technical efficiency is low and the dispersion of firms is relatively high. However, the usual caveat concerning direct intersectoral comparisons of production efficiency applies also here. Differences in institutional and market conditions, number and size of production units, specific factor inputs, make any comparison of firms' performance across industries difficult. 
Table 5. DEA results: relative technical efficiency (TE) of firms by industry (mean values, standard deviations and coefficients of variation)

\begin{tabular}{|c|c|c|c|c|}
\hline \multirow{2}{*}{ Industry } & \multirow{2}{*}{$\begin{array}{c}\text { Number of } \\
\text { firms }\end{array}$} & \multicolumn{3}{|c|}{ Relative technical efficiency (TE) } \\
\hline & & Mean value & $\begin{array}{l}\text { Standard } \\
\text { deviation }\end{array}$ & $\begin{array}{l}\text { Coefficient of } \\
\text { variation }\end{array}$ \\
\hline \multicolumn{5}{|l|}{ High R\&D intensity industries } \\
\hline Aircraft and spacecraft & 19 & 0.931 & 0.11 & 12.27 \\
\hline Pharmaceuticals & 148 & 0.791 & 0.15 & 19.48 \\
\hline Office accounting and computing machines & 45 & 0.810 & 0.17 & 20.51 \\
\hline Radio, television and communication equipment & 219 & 0.682 & 0.20 & 29.51 \\
\hline Medical, precision and optical instruments & 345 & 0.624 & 0.21 & 33.37 \\
\hline \multicolumn{5}{|l|}{ Medium-high R\&D intensity industries } \\
\hline Research and development & 34 & 0.789 & 0.29 & 36.69 \\
\hline Electrical machinery and apparatus n.e.c. & 833 & 0.705 & 0.17 & 23.71 \\
\hline Motor vehicles, trailers and semi-trailers & 343 & 0.785 & 0.14 & 17.38 \\
\hline Railroad equip. and transport equipment n.e.c. & 93 & 0.844 & 0.14 & 16.17 \\
\hline Chemicals, excluding pharmaceuticals & 482 & 0.809 & 0.12 & 14.38 \\
\hline Computer activities and related services & 427 & 0.568 & 0.22 & 37.96 \\
\hline Non-electrical machinery and equipment n.e.c. & 1998 & 0.608 & 0.16 & 25.55 \\
\hline \multicolumn{5}{|l|}{ Medium-low R\&D intensity industries } \\
\hline Other non-metallic mineral products & 945 & 0.727 & 0.14 & 19.05 \\
\hline Rubber and plastics products & 910 & 0.749 & 0.12 & 16.23 \\
\hline Coke, refined petroleum and nuclear products & 66 & 0.649 & 0.21 & 31.97 \\
\hline Post and communications & 27 & 0.930 & 0.14 & 14.59 \\
\hline Iron and steel & 564 & 0.785 & 0.12 & 14.74 \\
\hline Non-ferrous metals & 174 & 0.851 & 0.13 & 14.72 \\
\hline Shipbuilding and repairing & 65 & 0.798 & 0.14 & 17.54 \\
\hline Fabricated metal products & 1793 & 0.473 & 0.20 & 41.85 \\
\hline Education & 88 & 0.653 & 0.24 & 36.54 \\
\hline \multicolumn{5}{|l|}{ Low R\&D intensity industries } \\
\hline Mining and quarrying & 120 & 0.768 & 0.17 & 21.95 \\
\hline Other manufacturing, recycling & 373 & 0.786 & 0.13 & 16.99 \\
\hline Pulp, paper, paper products and printing & 912 & 0.580 & 0.16 & 27.65 \\
\hline Food products, beverages and tobacco & 1046 & 0.556 & 0.19 & 34.99 \\
\hline Textiles, textile products, leather and footwear & 2736 & 0.597 & 0.16 & 26.12 \\
\hline Wood, wood products and cork & 1250 & 0.776 & 0.12 & 16.07 \\
\hline Wholesale and retail trade, repairs & 3650 & 0.399 & 0.19 & 48.68 \\
\hline Electricity, gas and water supply & 152 & 0.688 & 0.22 & 31.43 \\
\hline Real estate, renting, other business services n.e.c. & 1489 & 0.426 & 0.20 & 48.08 \\
\hline Construction & 2196 & 0.298 & 0.18 & 59.57 \\
\hline Finance, insurance & - & - & - & - \\
\hline Transport and storage & 1476 & 0.353 & 0.22 & 63.02 \\
\hline Hotels and restaurants & 890 & 0.588 & 0.19 & 31.72 \\
\hline Publ. Admin. and defence; compulsory social security & - & - & - & - \\
\hline Health and social work & 657 & 0.678 & 0.18 & 26.38 \\
\hline Other community, social and personal services & 452 & 0.172 & 0.20 & 116.16 \\
\hline
\end{tabular}


Figure 2. Relative intensity in ICT and R\&D, mean value of firms' technical inefficiency by industry in Italy, 1997

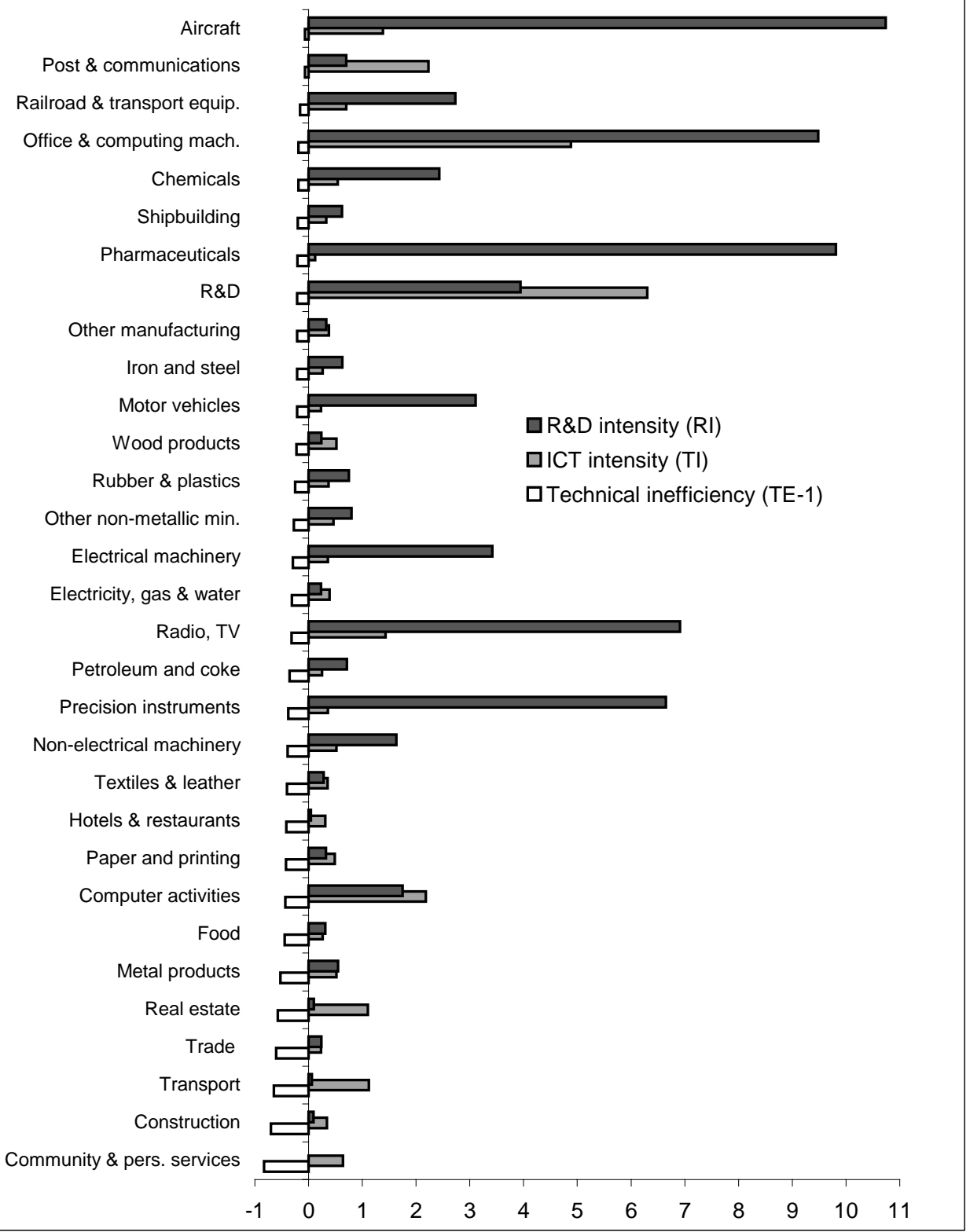




\subsection{Econometric results on correlation between ICT and technical efficiency}

The econometric estimates of parameters of the relation (3) applied as a cross section within the single examined industries are presented in Tables $6 \mathrm{a}-6 \mathrm{~d}$ along with the respective statistical tests. The regressions generally present a relatively low level of $R^{2}$, as is common in cross-sectional analyses with a large number of degrees of freedom, where the examined variables are normalised and "trend" effects are eliminated. We concentrate our comments only on parameter estimation concerning the ICT software (SOFT) and hardware (HDTC). The results confirm a strong positive correlation between ICT and firms' technical efficiency in the majority of cases. This positive correlation is observed for both the software and hardware components of ICT, with few exceptions. Tables 6a-6d present all parameter estimates and the respective statistical tests.

High R\&D intensity industries, paradoxically, seem to exhibit the smallest proportion of industries where a correlation can be noted between ICT and technical efficiency. No significant correlation is found for both ICT software and hardware in aircraft and spacecraft and office, accounting and computing machines, and for ICT hardware in pharmaceuticals. This negative result in three out of five high-tech industries can be explained by the fact that inefficiencies are much less evident in this type of industry, which are made up of ICT- and R\&D-intensive firms operating closer than other industries to the production technical frontier.

The other three knowledge-based groups of industries generally exhibit positive correlations. Exceptions are hardware in motor vehicles, and software in railroad and other transport equipment (within the medium-high R\&D intensive industry group), hardware in coke, refined petroleum and nuclear products and iron and steel, and both software and hardware in post and telecommunications and shipbuilding and repairs (within the medium-low $\mathrm{R} \& \mathrm{D}$ intensive industry group), hardware in pulp, paper and printing and food products and software in electricity, gas and water supply (within the low R\&D intensive industry group). Even considering these exceptions, it can be concluded that both the hardware and software components of ICT seem to be strongly related to technical efficiency of firms. These results do not appear to confirm previous findings, as for example those obtained by Paganetto, Becchetti and Londono Bedoya (2000), who claim that IT investments seem to have a positive and significant effect on firm efficiency when they are jointly considered, while software (telecommunications hardware) seems to have positive (negative) effects when individually considered.

In synthesis, the ICT-using firms are those that generally seem to take advantage from ICT in improving technical efficiency, while ICT-producing firms such as those belonging to the office, accounting and computing machines industry do not seem to exhibit technical efficiency that is correlated with ICT hardware and software. Although the recent literature shows that productivity growth rates are substantially lower in the ICT-using industries in respect to the ICT-producing industries, technical efficiency seems to be more positively correlated to ICT in the former group of industries. 
Table 6a. Parameter estimates: cross-sectional regressions for high R\&D intensity industries ${ }^{\star}$

\begin{tabular}{|c|c|c|c|c|c|c|c|c|c|}
\hline Parameter & \multicolumn{2}{|c|}{ Aircraft } & \multicolumn{2}{|c|}{ Pharmaceuticals } & \multicolumn{2}{|c|}{$\begin{array}{c}\text { Office and } \\
\text { computing } \\
\text { machines }\end{array}$} & \multicolumn{2}{|c|}{$\begin{array}{c}\text { Radio, TV and } \\
\text { communication } \\
\text { equipment }\end{array}$} & $\begin{array}{c}\text { Medical and } \\
\text { precision } \\
\text { instruments }\end{array}$ \\
\hline$\beta_{0}$ & 0.72824 & $(0.20292)$ & 0.58388 & $(0.07489)$ & 0.76196 & $(0.12483)$ & 0.54956 & $(0.04915)$ & $0.32329(0.04782)$ \\
\hline$\beta_{1}($ SOFT $)$ & 0.53245 & (3.31634) & 0.27943 & $(0.13252)$ & 0.07340 & (0.18209) & 0.32952 & $(0.10637)$ & $0.20960(0.06361)$ \\
\hline$\beta_{2}$ (HDTC) & 0.60277 & (1.44683) & 0.10821 & $(0.19036)$ & -0.13278 & (0.18578) & 0.22098 & $(\mathbf{0 . 0 9 0 6 3 )}$ & $0.21392(0.11084)$ \\
\hline$\beta_{3}(\mathrm{R} \& \mathrm{D})$ & -0.72178 & $(0.77476)$ & -0.67076 & $(0.40344)$ & 0.23185 & $(0.39606)$ & -0.84584 & $(0.34372)$ & $0.12660(0.25793)$ \\
\hline$\beta_{4}$ (CLUOP) & 0.00365 & $(0.00277)$ & -0.00039 & $(0.00047)$ & 0.00022 & (0.00104) & 0.00012 & $(0.00021)$ & $0.00003(0.00016)$ \\
\hline$\beta_{5}($ CLUID $)$ & -0.00191 & $(0.00211)$ & 0.00043 & $(0.00054)$ & -0.00008 & $(0.00161)$ & 0.00028 & $(0.00026)$ & $0.00050(0.00016)$ \\
\hline$\beta_{6}$ (SIZE) & 0.14815 & $(0.14539)$ & 0.05012 & $(0.02670)$ & 0.21518 & $(0.06142)$ & 0.15766 & $(0.02622)$ & $0.08473(0.02076)$ \\
\hline$\beta_{7}(\mathrm{RIP})$ & -0.01088 & $(0.10110)$ & 0.03230 & $(0.05077)$ & -0.00232 & $(0.08304)$ & -0.01433 & $(0.04400)$ & $0.03503(0.04263)$ \\
\hline$\beta_{8}(\mathrm{~K} / \mathrm{L})$ & -0.00090 & $(0.00218)$ & -0.00047 & $(0.00016)$ & -0.00067 & $(0.00051)$ & -0.00037 & $(0.00028)$ & $-0.00048(0.00022)$ \\
\hline$\beta_{9}$ (FATTAD) & 0.00013 & $(0.00059)$ & 0.00018 & $(0.00005)$ & 0.00010 & (0.00009) & 0.00032 & $(0.00006)$ & $0.00088(0.00007)$ \\
\hline$\beta_{10}(\mathrm{DEB} / \mathrm{OC})$ & 0.01056 & $(0.01141)$ & -0.00082 & $(0.00118)$ & 0.00070 & $(0.00080)$ & 0.00013 & $(0.00016)$ & $0.00062(0.00026)$ \\
\hline$\beta_{11}$ (SKILL) & 0.05798 & $(0.60165)$ & 0.15794 & $(0.06963)$ & -0.04163 & (0.10203) & -0.03013 & $(0.05065)$ & $-0.00239(0.03590)$ \\
\hline $\mathrm{R}^{2}$ & 0.6308 & & 0.3552 & & 0.3597 & & 0.3577 & & 0.4460 \\
\hline Adj. $R^{2}$ & 0.0507 & & 0.3030 & & 0.1462 & & 0.3235 & & 0.4277 \\
\hline F value & 1.09 & & 6.81 & & 1.69 & & 10.48 & & 24.37 \\
\hline D.F. & 7 & & 136 & & 33 & & 207 & & 333 \\
\hline
\end{tabular}

*Standard errors in parentheses. 
DSTI/DOC(2002)13

Table 6b. Parameter estimates: cross-sectional regressions for medium-high R\&D intensity industries*

\begin{tabular}{|c|c|c|c|c|c|c|c|c|c|c|c|c|c|c|c|c|}
\hline Parameter & \multicolumn{2}{|c|}{$\begin{array}{l}\text { Research and } \\
\text { development }\end{array}$} & \multicolumn{2}{|c|}{$\begin{array}{c}\text { Electrical } \\
\text { machinery n.e.c }\end{array}$} & \multicolumn{2}{|c|}{$\begin{array}{l}\text { Motor vehicles, } \\
\text { trailers and semi- } \\
\text { trailers }\end{array}$} & \multicolumn{2}{|c|}{$\begin{array}{l}\text { Railroad equip. } \\
\text { and transport } \\
\text { equipment n.e.c. }\end{array}$} & \multicolumn{2}{|c|}{$\begin{array}{c}\text { Chemicals, } \\
\text { excluding } \\
\text { pharmaceuticals } \\
\end{array}$} & \multicolumn{2}{|c|}{$\begin{array}{c}\text { Computer } \\
\text { activities and } \\
\text { related services }\end{array}$} & \multicolumn{2}{|c|}{$\begin{array}{l}\text { Non-electrical } \\
\text { machinery and } \\
\text { equipment n.e.c }\end{array}$} & \multicolumn{2}{|c|}{ Education } \\
\hline$\beta_{0}$ & 0.73608 & $(0.30992)$ & 0.49355 & $(0.02392)$ & 0.61954 & $(0.03313)$ & 0.70638 & $(0.06285)$ & 0.60635 & $(0.02810)$ & 0.36709 & $(0.08331)$ & 0.46259 & $(0.01745)$ & 0.58249 & $(0.10854)$ \\
\hline$\beta_{1}($ SOFT) & -0.18783 & (1.10260) & 0.30345 & $(0.06031)$ & 0.23056 & $(\mathbf{0 . 0 6 2 8 5})$ & 0.08847 & $(0.11226)$ & 0.14488 & $(0.05296)$ & -0.02388 & $(0.04670)$ & 0.27937 & $(0.03019)$ & 0.35279 & (0.22513) \\
\hline$\beta_{2}$ (HDTC) & -0.29893 & $(0.24377)$ & 0.27109 & $(0.05788)$ & 0.02609 & $(0.11107)$ & -0.61728 & $(0.40555)$ & 0.12794 & $(0.09731)$ & 0.06762 & $(0.03579)$ & 0.11737 & $(0.03652)$ & -0.05186 & (0.15779) \\
\hline$\beta_{3}(\mathrm{R} \& \mathrm{D})$ & 0.21630 & $(0.14931)$ & -1.02804 & $(0.23308)$ & -0.45364 & $(0.18365)$ & -2.19568 & $(0.65756)$ & -0.77910 & $(0.30550)$ & -0.10145 & $(0.06114)$ & -0.03644 & $(0.03016)$ & 0.94647 & $(0.76146)$ \\
\hline$\beta_{4}$ (CLUOP) & -0.00126 & $(0.00159)$ & 0.00081 & $(0.00030)$ & 0.00139 & $(0.00058)$ & 0.00005 & $(0.00021)$ & 0.00074 & (0.00034) & 0.00073 & $(0.00043)$ & 0.00034 & $(0.00015)$ & -0.00089 & $(0.00089)$ \\
\hline$\beta_{5}(\mathrm{CLUID})$ & 0.00005 & $(0.00223)$ & 0.00014 & $(0.00010)$ & 0.00054 & $(0.00022)$ & -0.00011 & $(0.00025)$ & 0.00042 & $(0.00017)$ & 0.00120 & $(0.00047)$ & 0.00006 & $(0.00006)$ & -0.00191 & $(0.00146)$ \\
\hline$\beta_{6}$ (SIZE) & -0.00842 & $(0.08336)$ & 0.10134 & $(0.01073)$ & 0.05026 & $(0.01349)$ & 0.02683 & $(0.02933)$ & 0.04852 & (0.01048) & 0.10113 & $(0.02264)$ & 0.10466 & $(0.00660)$ & 0.31330 & $(0.15501)$ \\
\hline$\beta_{7}(\mathrm{RIP})$ & 0.06267 & $(0.11497)$ & 0.04271 & $(0.01897)$ & -0.03505 & $(0.02237)$ & 0.17489 & $(0.05575)$ & 0.04192 & $(0.01913)$ & -0.00240 & $(0.03039)$ & -0.01181 & $(0.01506)$ & -0.00763 & $(0.06832)$ \\
\hline$\beta_{8}(\mathrm{~K} / \mathrm{L})$ & -0.00081 & $(0.00017)$ & -0.00076 & $(0.00011)$ & -0.00034 & $(0.00007)$ & -0.00056 & $(0.00035)$ & -0.00010 & $(0.00004)$ & -0.00046 & $(0.00019)$ & -0.00062 & $(0.00006)$ & -0.00065 & $(0.00112)$ \\
\hline$\beta_{9}($ FATTAD $)$ & 0.00077 & $(0.00034)$ & 0.00050 & $(0.00003)$ & 0.00037 & $(0.00004)$ & 0.00017 & $(0.00008)$ & 0.00011 & $(0.00002)$ & 0.00049 & $(0.00009)$ & 0.00050 & $(0.00002)$ & 0.00076 & $(0.00028)$ \\
\hline$\beta_{10}(\mathrm{DEB} / \mathrm{OC})$ & 0.00050 & $(0.00128)$ & -0.00001 & $(0.00003)$ & -0.00005 & $(0.00051)$ & -0.00055 & $(0.00017)$ & 0.00008 & $(0.00012)$ & $3.79 \mathrm{E}-6$ & (9.19E-6) & 0.00003 & $(0.00007)$ & 0.00012 & $(0.00171)$ \\
\hline$\beta_{11}$ (SKILL) & 0.08209 & $(0.33003)$ & -0.04378 & $(0.02774)$ & -0.05968 & $(0.05936)$ & -0.06302 & $(0.09576)$ & 0.05764 & $(0.02610)$ & 0.01439 & $(0.01439)$ & -0.03789 & $(0.01671)$ & 0.13141 & $(0.11752)$ \\
\hline $\mathrm{R}^{2}$ & 0.6807 & & 0.3864 & & 0.3647 & & 0.4385 & & 0.3037 & & 0.2503 & & 0.4194 & & 0.2494 & \\
\hline Adj. $R^{2}$ & 0.5210 & & 0.3782 & & 0.3435 & & 0.3623 & & 0.2874 & & 0.2304 & & 0.4162 & & 0.1407 & \\
\hline $\mathrm{F}$ value & 4.26 & & 47.00 & & 17.27 & & 5.75 & & 18.64 & & 12.60 & & 130.40 & & 2.30 & \\
\hline D.F. & 22 & & 821 & & 331 & & 81 & & 470 & & 415 & & 1986 & & & \\
\hline
\end{tabular}

*Standard errors in parentheses. 
DSTI/DOC(2002)13

Table 6c. Parameter estimates: cross-sectional regressions for medium-low R\&D intensity industries*

\begin{tabular}{|c|c|c|c|c|c|c|c|c|c|c|c|c|c|c|c|c|}
\hline \multirow{2}{*}{$\begin{array}{l}\text { Parameter } \\
\beta_{0}\end{array}$} & \multicolumn{2}{|c|}{$\begin{array}{l}\text { Other non-metallic } \\
\text { mineral products }\end{array}$} & \multicolumn{2}{|c|}{$\begin{array}{l}\text { Rubber and plastics } \\
\text { products }\end{array}$} & \multicolumn{2}{|c|}{$\begin{array}{c}\text { Coke, refined } \\
\text { petroleum and } \\
\text { nuclear products }\end{array}$} & \multicolumn{2}{|c|}{$\begin{array}{l}\text { Post and } \\
\text { telecommunications }\end{array}$} & \multicolumn{2}{|c|}{ Iron and steel } & \multicolumn{2}{|c|}{$\begin{array}{l}\text { Non-ferrous } \\
\text { metals }\end{array}$} & \multicolumn{2}{|c|}{$\begin{array}{l}\text { Shipbuilding and } \\
\text { repairing }\end{array}$} & \multicolumn{2}{|c|}{$\begin{array}{l}\text { Fabricated metal } \\
\text { products }\end{array}$} \\
\hline & 0.51628 & $(0.01710)$ & 0.61310 & $(0.01721)$ & 0.48952 & $(0.09100)$ & 0.73346 & $(0.13677)$ & 0.58618 & $(0.02322)$ & 0.60410 & $(0.05453)$ & 0.62496 & $(0.08467)$ & 0.44738 & $(0.01929)$ \\
\hline$\beta_{1}($ SOFT $)$ & 0.27533 & (0.05918) & 0.21792 & $(0.03500)$ & 0.32649 & $(0.18586)$ & 0.36316 & (1.30151) & 0.19501 & (0.04688) & -0.21088 & $(0.87867)$ & 0.01667 & $(0.71773)$ & 0.37012 & $(0.05191)$ \\
\hline$\beta_{2}$ (HDTC) & 1.13752 & $(0.16507)$ & 0.32906 & $(0.12332)$ & 1.35555 & $(2.06030)$ & 0.12173 & $(0.26334)$ & -0.07329 & (0.10943) & 0.22679 & $(0.49058)$ & -0.38494 & $(0.42614)$ & 0.48364 & $(0.08162)$ \\
\hline$\beta_{3}(\mathrm{R} \& \mathrm{D})$ & -0.23362 & $(0.10941)$ & -0.48354 & $(0.29530)$ & 0.29077 & $(2.18459)$ & 0.32901 & $(2.26576)$ & -1.59333 & $(0.62832)$ & -0.58081 & $(0.68205)$ & 1.59302 & $(1.86981)$ & -1.85141 & $(0.38892)$ \\
\hline$\beta_{4}(\mathrm{CLUOP})$ & 0.00150 & $(0.00032)$ & 0.00027 & $(0.00012)$ & 0.00023 & $(0.00104)$ & 0.00077 & $(0.00144)$ & 0.00116 & $(0.00034)$ & 0.00390 & $(0.00084)$ & 0.00169 & $(0.00145)$ & -0.00009 & $(0.00028)$ \\
\hline$\beta_{5}$ (CLUID) & 0.00020 & $(0.00006)$ & 0.00012 & $(0.00007)$ & 0.00166 & $(0.00010)$ & 0.00004 & $(0.00074)$ & 0.00020 & (0.00009) & $-3.19 \mathrm{E}-6$ & $(0.00018)$ & 0.00049 & $(0.00021)$ & -0.00003 & $(0.00005)$ \\
\hline$\beta_{6}(\mathrm{SIZE})$ & 0.05842 & $(0.00956)$ & 0.05713 & $(0.00985)$ & -0.06801 & $(0.05435)$ & 0.02273 & $(0.14565)$ & 0.05083 & $(0.00976)$ & 0.05196 & $(0.02140)$ & -0.32671 & $(0.06825)$ & -0.01837 & $(0.01225)$ \\
\hline$\beta_{7}(\mathrm{RIP})$ & 0.04860 & $(0.01095)$ & 0.05137 & $(0.01388)$ & 0.06796 & $(0.07191)$ & 0.13143 & $(0.13305)$ & 0.04504 & $(0.01698)$ & 0.04981 & $(0.03825)$ & 0.00937 & $(0.05291)$ & 0.00328 & $(0.01399)$ \\
\hline$\beta_{8}(\mathrm{~K} / \mathrm{L})$ & -0.00026 & $(0.00004)$ & -0.00021 & $(0.00006)$ & 0.00004 & $(0.00007)$ & -0.00034 & $(0.00040)$ & -0.00021 & $(0.00005)$ & -0.00062 & $(0.00015)$ & -0.00042 & $(0.00016)$ & -0.00171 & $(0.00008)$ \\
\hline$\beta_{9}($ FATTAD $)$ & 0.00037 & $(0.00001)$ & 0.00021 & $(0.00002)$ & 0.00003 & $(0.00001)$ & 0.00004 & $(0.00014)$ & 0.00017 & $(0.00002)$ & 0.00008 & $(0.00002)$ & 0.00119 & $(0.00022)$ & 0.00059 & $(0.00003)$ \\
\hline$\beta_{10}(\mathrm{DEB} / \mathrm{OC})$ & -0.00001 & $(0.00010)$ & -0.00063 & $(0.00019)$ & -0.00054 & $(0.00042)$ & 0.00014 & $(0.00120)$ & 0.00001 & $(0.00002)$ & -0.00011 & $(0.00008)$ & -0.00112 & $(0.00089)$ & -0.00005 & $(0.00004)$ \\
\hline$\beta_{11}(\mathrm{SKILL})$ & -0.06806 & $(0.03470)$ & 0.04332 & $(0.03141)$ & -0.20645 & $(0.16358)$ & 0.06053 & $(0.14895)$ & 0.12381 & $(0.04727)$ & -0.00658 & $(0.08421)$ & -0.56074 & $(0.21922)$ & -0.05936 & $(0.03274)$ \\
\hline $\mathrm{R}^{2}$ & 0.3821 & & 0.2278 & & 0.3448 & & 0.2248 & & 0.3535 & & 0.3099 & & 0.5486 & & 0.3495 & \\
\hline Adj. $R^{2}$ & 0.3748 & & 0.2184 & & 0.2113 & & 0.3436 & & 0.3406 & & 0.2630 & & 0.4549 & & 0.3455 & \\
\hline F value & 52.45 & & 24.08 & & 2.58 & & 0.40 & & 27.44 & & 6.61 & & 5.85 & & 86.99 & \\
\hline D.F. & 933 & & 898 & & 54 & & 15 & & 552 & & 162 & & 53 & & 1781 & \\
\hline
\end{tabular}

*Standard errors in parentheses. 
Table 6d. Parameter estimates: cross-sectional regressions for low R\&D intensity industries*

\begin{tabular}{|c|c|c|c|c|c|c|c|c|c|c|c|c|c|c|}
\hline \multirow{2}{*}{$\begin{array}{l}\text { Parameter } \\
\beta_{0}\end{array}$} & \multicolumn{2}{|c|}{$\begin{array}{l}\text { Mining and } \\
\text { quarrying }\end{array}$} & \multicolumn{2}{|c|}{$\begin{array}{c}\text { Other } \\
\text { manufacturing, } \\
\text { recycling }\end{array}$} & \multicolumn{2}{|c|}{$\begin{array}{l}\text { Pulp, paper, paper } \\
\text { products and } \\
\text { printing }\end{array}$} & \multicolumn{2}{|c|}{$\begin{array}{c}\text { Food products, } \\
\text { beverages and } \\
\text { tobacco }\end{array}$} & \multicolumn{2}{|c|}{$\begin{array}{c}\text { Textile, textile } \\
\text { products, leather } \\
\text { and footwear }\end{array}$} & \multicolumn{2}{|c|}{$\begin{array}{l}\text { Wood, wood } \\
\text { products and cork }\end{array}$} & \multicolumn{2}{|c|}{$\begin{array}{c}\text { Wholesale and } \\
\text { retail trade, } \\
\text { repairs }\end{array}$} \\
\hline & 0.52516 & $(0.05448)$ & 0.58194 & $(0.03632)$ & 0.43279 & $(0.01649)$ & 0.47706 & $(0.01863)$ & 0.45743 & $(0.00778)$ & 0.57260 & $(0.01292)$ & 0.32505 & $(0.00987)$ \\
\hline$\beta_{1}($ SOFT) & -5.23050 & $(4.08821)$ & 0.40480 & $(0.18446)$ & 0.27138 & $(0.06651)$ & 0.28426 & $(0.05190)$ & 0.14315 & $(0.03956)$ & 0.21481 & $(0.02779)$ & 0.33518 & $(0.03538)$ \\
\hline$\beta_{2}$ (HDTC) & 1.00853 & (1.20681) & 0.22214 & $(0.11808)$ & 0.02450 & $(0.04945)$ & 0.20703 & $(0.23069)$ & 0.10771 & $(0.03998)$ & 0.55516 & $(0.08045)$ & 0.13243 & $(0.02688)$ \\
\hline$\beta_{3}(\mathrm{R} \& \mathrm{D})$ & -0.62117 & $(0.51257)$ & -0.76821 & (0.46104) & -0.21694 & $(0.14038)$ & -0.46076 & $(0.26990)$ & -0.38283 & $(0.15169)$ & -0.36305 & $(0.07362)$ & -0.33494 & $(0.22548)$ \\
\hline$\beta_{4}$ (CLUOP) & 0.00151 & $(0.00095)$ & 0.00103 & $(0.00036)$ & 0.00004 & $(0.00003)$ & 0.00026 & $(0.00027)$ & 0.00013 & $(0.00004)$ & 0.00188 & $(0.00026)$ & 0.00037 & (0.00009) \\
\hline$\beta_{5}(\mathrm{CLUID})$ & 0.00087 & $(0.00043)$ & 0.00027 & $(0.00012)$ & 0.00009 & $(0.00004)$ & 0.00010 & (0.00010) & -0.00004 & $(0.00003)$ & 0.00018 & $(0.00004)$ & 0.00012 & (0.00004) \\
\hline$\beta_{6}(\mathrm{SIZE})$ & -0.01449 & $(0.05935)$ & 0.07149 & $(0.01832)$ & 0.06688 & $(0.01126)$ & -0.09849 & (0.01148) & 0.06417 & $(0.00734)$ & 0.07147 & $(0.00947)$ & 0.03580 & $(0.00878)$ \\
\hline$\beta_{7}(\mathrm{RIP})$ & 0.10475 & $(0.04012)$ & 0.07615 & $(0.03154)$ & 0.01783 & $(0.01562)$ & 0.02159 & $(0.01293)$ & 0.06557 & (0.00777) & 0.04061 & $(0.01027)$ & -0.00238 & $(0.00878)$ \\
\hline$\beta_{8}(\mathrm{~K} / \mathrm{L})$ & -0.00003 & $(0.00009)$ & -0.00007 & $(0.00009)$ & -0.00006 & $(0.00005)$ & -0.00059 & (0.00004) & -0.00014 & $(0.00006)$ & -0.00005 & $(0.00001)$ & -0.00083 & $(0.00854)$ \\
\hline$\beta_{9}(\mathrm{FATTAD})$ & 0.00004 & $(0.00003)$ & 0.00010 & $(0.00002)$ & 0.00036 & $(0.00002)$ & 0.00024 & $(0.00001)$ & 0.00033 & $(0.00001)$ & 0.00029 & $(0.00002)$ & 0.00006 & $(0.00004)$ \\
\hline$\beta_{10}(\mathrm{DEB} / \mathrm{OC})$ & -0.00072 & $(0.00039)$ & -0.00035 & $(0.00021)$ & -0.00007 & $(0.00002)$ & -0.00003 & $(0.00018)$ & $3.424 \mathrm{E}-7$ & (3.358E-7) & -0.00009 & $(0.00004)$ & -0.00002 & $(2.62 \mathrm{E}-6)$ \\
\hline$\beta_{11}($ SKILL $)$ & 0.05834 & $(0.11594)$ & 0.13032 & $(0.04049)$ & 0.01423 & $(0.01873)$ & 0.01639 & $(0.03131)$ & -0.00633 & $(0.01976)$ & -0.01655 & $(0.02192)$ & 0.07526 & $(0.00955)$ \\
\hline $\mathrm{R}^{2}$ & 0.2686 & & 0.2610 & & 0.3955 & & 0.3814 & & 0.3040 & & 0.3882 & & 0.2706 & \\
\hline Adj. $R^{2}$ & 0.1941 & & 0.2385 & & 0.3881 & & 0.3748 & & 0.3012 & & 0.3827 & & 0.2684 & \\
\hline F value & 3.61 & & 11.59 & & 53.54 & & 57.96 & & 108.19 & & 71.40 & & 122.68 & \\
\hline D.F. & 108 & & 361 & & 900 & & 1034 & & 2724 & & 1238 & & 3638 & \\
\hline
\end{tabular}

*Standard errors in parentheses. 
Table 6d. (continued)

DSTI/DOC(2002)13

\begin{tabular}{|c|c|c|c|c|c|c|c|c|c|c|c|c|c|c|}
\hline \multirow{2}{*}{$\begin{array}{l}\text { Parameter } \\
\beta_{0}\end{array}$} & \multicolumn{2}{|c|}{$\begin{array}{l}\text { Electricity, gas, and } \\
\text { water supply }\end{array}$} & \multicolumn{2}{|c|}{$\begin{array}{c}\text { Real estate, } \\
\text { renting, other } \\
\text { business services }\end{array}$} & \multicolumn{2}{|c|}{ Construction } & \multicolumn{2}{|c|}{$\begin{array}{c}\text { Transport and } \\
\text { storage }\end{array}$} & \multicolumn{2}{|c|}{$\begin{array}{l}\text { Hotels and } \\
\text { restaurants }\end{array}$} & \multicolumn{2}{|c|}{$\begin{array}{c}\text { Health and social } \\
\text { work }\end{array}$} & \multicolumn{2}{|c|}{$\begin{array}{l}\text { Other community, } \\
\text { social and } \\
\text { personal services }\end{array}$} \\
\hline & 0.30385 & $(0.13495)$ & 0.32488 & $(0.01237)$ & 0.25131 & $(0.01376)$ & 0.23726 & $(0.01372)$ & 0.41781 & $(0.01562)$ & 0.14839 & $(0.02571)$ & 0.50309 & $(0.01880)$ \\
\hline$\beta_{1}($ SOFT $)$ & 0.12042 & $(0.53515)$ & 0.10626 & $(0.04640)$ & 0.34052 & $(0.05406)$ & 0.18131 & $(0.06584)$ & 0.24169 & (0.11449) & -0.06691 & $(0.27240)$ & 0.12468 & $(0.08355)$ \\
\hline$\beta_{2}$ (HDTC) & 1.07482 & $(0.42706)$ & 0.07053 & (0.02569) & 0.15191 & $(0.05267)$ & 0.14540 & $(0.05546)$ & 0.50545 & $(0.08463)$ & 0.13793 & $(0.08628)$ & 0.10726 & $(0.04371)$ \\
\hline$\beta_{3}(\mathrm{R} \& \mathrm{D})$ & -6.09007 & (2.94507) & -1.02479 & $(0.26772)$ & -0.00002 & $(0.00001)$ & -0.76085 & $(0.33310)$ & -0.38765 & (0.14037) & 0.00059 & $(0.03370)$ & -0.29375 & $(0.22131)$ \\
\hline$\beta_{4}$ (CLUOP) & 0.00088 & $(0.00057)$ & 0.00030 & $(0.00011)$ & -0.00035 & $(0.00023)$ & -0.00005 & $(0.00004)$ & 0.00008 & $(0.00008)$ & -0.00032 & $(0.00024)$ & 0.00034 & $(0.00016)$ \\
\hline$\beta_{5}$ (CLUID) & 0.00126 & $(0.00091)$ & 0.00010 & $(0.00004)$ & -0.00007 & $(0.00004)$ & -0.00008 & (0.00004) & 0.00021 & $(0.00007)$ & 0.00013 & (0.00009) & 0.00016 & $(0.00015)$ \\
\hline$\beta_{6}(\mathrm{SIZE})$ & 0.03201 & $(0.03272)$ & 0.12254 & $(0.01036)$ & 0.00174 & (0.01219) & 0.04927 & $(0.01162)$ & 0.15188 & $(0.01779)$ & -0.04846 & $(0.02110)$ & 0.06479 & $(0.01241)$ \\
\hline$\beta_{7}(\mathrm{RIP})$ & 0.06249 & $(0.04366)$ & -0.02374 & $(0.01223)$ & -0.01990 & $(0.00945)$ & 0.03400 & $(0.01374)$ & 0.05099 & $(0.01329)$ & -0.00612 & $(0.02312)$ & -0.01252 & $(0.01343)$ \\
\hline$\beta_{8}(\mathrm{~K} / \mathrm{L})$ & -0.00002 & $(0.00002)$ & -0.00003 & $(0.00001)$ & -0.00006 & $(0.00002)$ & 0.00001 & $(0.00002)$ & -0.00003 & $(0.00003)$ & -0.00004 & $(0.00006)$ & -0.00056 & $(0.00012)$ \\
\hline$\beta_{9}$ (FATTAD) & 0.00021 & $(0.00004)$ & 0.00038 & $(0.00002)$ & 0.00040 & $(0.00002)$ & 0.00027 & $(0.00002)$ & 0.00075 & $(0.00007)$ & 0.00022 & $(0.00002)$ & 0.00164 & $(0.00011)$ \\
\hline$\beta_{10}(\mathrm{DEB} / \mathrm{OC})$ & 0.00482 & $(0.00238)$ & $-4.26 \mathrm{E}-6$ & $(1.70 \mathrm{E}-6)$ & $1.87 \mathrm{E}-6$ & $(1.44 \mathrm{E}-6)$ & 0.00014 & $(0.00010)$ & 0.00002 & $(0.00008)$ & $-2.27 \mathrm{E}-6$ & $(4.15 \mathrm{E}-6)$ & $1.04 \mathrm{E}-6$ & (3.34E-6) \\
\hline$\beta_{11}$ (SKILL) & 0.11812 & $(0.10229)$ & 0.04943 & $(0.01293)$ & -0.05137 & $(0.02429)$ & 0.04303 & (0.01897) & 0.06441 & $(0.03352)$ & 0.01045 & $(0.03146)$ & -0.00412 & $(0.01688)$ \\
\hline $\mathrm{R}^{2}$ & 0.2828 & & 0.3075 & & 0.1876 & & 0.2312 & & 0.2498 & & 0.2173 & & 0.3312 & \\
\hline Adj. $R^{2}$ & 0.2265 & & 0.3024 & & 0.1836 & & 0.2254 & & 0.2404 & & 0.1974 & & 0.3198 & \\
\hline F value & 5.02 & & 59.63 & & 45.86 & & 40.01 & & 26.58 & & 10.93 & & 29.03 & \\
\hline
\end{tabular}




\section{Concluding remarks}

This paper has shown that ICT is positively related to firms' technical efficiency in many industries. Improvement in technical efficiency may constitute an important part of productivity gains, especially in those industries where many firms do not operate on the production possibility frontier. This result is in line with recent empirical studies that have begun to put in evidence correlations between ICT investment and productivity gains in a number of advanced countries, including Italy.

The positive effects of ICT on firms' technical efficiency have been found in all four groups of industries defined according to the degree of R\&D intensity in production. This result permits us to confirm that ICT is a valid factor for firms to capture quickly and efficiently the information they need and to optimise their production processes. As expected, high and medium-high R\&D intensity industries show the highest mean value of firms' technical efficiency with the lowest dispersion of production units.

Technical efficiency in a number of high $R \& D$ intensity industries does not seem, however, to be significantly affected by ICT. This apparently paradoxical result can be explained by the fact that the majority of firms in these industries operate close to the production frontier. These firms are also ICTintensive and do not have scope for further action to improve technical efficiency within the given technology by increasing the intensity of use of this type of capital good.

Both the hardware and software components of ICT seem in general to be strongly correlated to firms' technical efficiency. This result is not in line with previous results obtained for Italy by empirical studies that have examined other firm-level information. In at least one study based on a database smaller than that examined here, software appears to have positive effects on firm efficiency, while telecommunication hardware seems to have negative effects. Complementary positive effects of software and hardware on technical efficiency are instead found in the majority of industries examined.

The firms operating in ICT-using industries are in general those that seem to take the most advantage from ICT in improving technical efficiency, while the firms belonging to the ICT-producing sector do not seem to exhibit strong correlations between ICT hardware and software and technical efficiency. Although productivity gains have been higher in this last sector than in the ICT-using industries, technical efficiency seems to be more affected by ICT in the former group of industries.

The analysis presented in this paper can be extended in many directions. The effects of ICT on technical efficiency may be studied, not only across the firms in a single period of time, but also in an intertemporal context using panel data. This will be a further step in the present line of research. Moreover, the effects of ICT on technological change can be assessed by studying not only the consequent changes in technical efficiency, but also changes in the production frontier within each industry. This kind of analysis requires information on time series of prices and quantities of outputs and inputs at the level of the most efficient firms and will be developed by integrating different micro databases. 
DSTI/DOC(2002)13

\section{ANNEX 1. ICT IN ITALY: AN INTERNATIONAL PERSPECTIVE}

The great expansion of information and communication technologies that has taken place during the last decade has opened up a new age of opportunities and challenges in many economic regions all over the world. The development of Internet-related activities has put the computer in a central position as a primary communication tool by linking information and computing technologies to a world wide communication system. The ICT acronym itself was coined recently. This process is strongly related to R\&D, innovation activities, changes in skills of workers and human capital, reorganisation of firms, financial resources, infrastructures, and other not less important factors. Not all countries are taking advantage of this kind of revolution in the same way and at the same pace.

\section{A1.1 The ICT-consuming sector}

The diffusion of production and utilisation of ICT appears in Italy significantly lower than in other economically advanced countries. Among the G7 countries, Italy has the lowest share of ICT expenditure in GDP. In 1992-1999, this share was almost half of that observed in the United States and the United Kingdom and significantly lower than that of France and Germany. Italy's share of ICT in the productive capital stock is even smaller. In 1996, this share was less than one third of that observed in the United States and less than half of that of Canada and the United Kingdom, while France and Germany registered shares about $50 \%$ higher than in Italy.

The penetration of PCs per 100 inhabitants in 1999 was almost one sixth of that in the United States and less than half of that in the United Kingdom, Germany and France. The share of Internet hosts per 1000 inhabitants in September 1999 was one eighteenth of that in the United States, one fourth of that in the United Kingdom and half of that in Germany and Japan. A similar picture can be observed by considering the diffusion indicator of secure servers. This indicator measures the number of servers with a secure software used for transactions of goods and services, which is necessary to develop e-commerce and e-government activities.

\section{A1.2 ICT capital formation}

The ranking of countries in the diffusion of the ICT does not seem to be destined to change substantially in the foreseeable future. This conclusion can be reached by examining the speed of capital formation in ICT, although different patterns of growth in ICT capital stock can be estimated using the available statistical information and alternative deflators of ICT capital services. If national statistics on ICT deflators are used, capital formation in ICT appears positively correlated to the countries' relative intensity in ICT, meaning that the gap between the countries examined has widened and probably will continue to do so in the coming years.

Italy's share of ICT investments in non-residential gross fixed capital formation has turned out to be about half of that observed in the United States and the United Kingdom and about 10\% lower than that in France and Germany. Although some caveats should be taken into account when aggregate data are compared, particularly in cases where the sectoral composition of consumption activities differs across countries, the 
current differentials of growth rates of the ICT capital stock certainly reflect, at least in part, Italy's lagging behind in many sectors in this field with respect to the other G7 countries.

\section{A1.3 The ICT-producing sector}

Italy's ICT-producing sector is not very different in relative size from that of France and Germany, while it is substantially smaller than that of the United States and the United Kingdom. The ICT shares in business sector value added and employment are in Italy respectively 5.8\% and 3.5\% against shares in France equal to $5.3 \%$ and $4.0 \%$ and in Germany equal to $6.1 \%$ and $3.1 \%$, but at some distance from those in the United States, equal to $8.7 \%$ and $3.9 \%$, and the United Kingdom, equal to $8.4 \%$ and $4.8 \%$.

The ICT-producing sector in Italy appears more concentrated in telecommunications and other ICT services than in other G7 countries. Manufacturing ICT is relatively undersized in Italy, with a share in business sector value added that is less than half of that in the United States and Japan and much smaller than that in the United Kingdom, Germany and France. Italy's ICT share in business sector employment is also the lowest, particularly in manufacturing ICT, even though the shares in employment have a lower variance with respect to the shares in value added among the countries examined.

\section{A1.4 External trade}

External trade of ICT products, mainly concentrated in manufacturing ICT, reflects the relative weakness of Italy's ICT-producing sector, with an export ratio (defined as the ratio between exports and domestic production) lower than half of those in the three other major European countries. Comparison with the United States and Japan is not straightforward, since the size of the respective economies affects the degree of openness to international trade. However, export ratios in these countries are higher than in Italy. Import penetration (defined as the ratio between imports and domestic demand) is much lower in Italy than in the three other major European countries, reflecting a minor propensity to use ICT.

The trade balance in relative terms, expressed as the ratio to the trade volume (exports plus imports) and domestic production, reveals a particular weakness of the Italian ICT sector in comparison to the trade performance of the three major European countries. The overall trade deficit that was registered in 1997 has been, respectively, $22.1 \%$ and $5.9 \%$ of trade volume and domestic production, against $2.7 \%$ and $1.5 \%$ in France, $5.7 \%$ and $3.2 \%$ in Germany, $0.2 \%$ and $0.1 \%$ in the United Kingdom. Particularly critical is Italy's trade performance in the manufacturing ICT sector, with a trade deficit equal to $21.1 \%$ of domestic production while France, Germany and the United Kingdom registered trade deficit ratios of a few percentage points.

\section{A1.5 Impact of the reorganisation of work practices}

The lesser penetration of the ICT in Italy has been indirectly reflected by the associated reorganisation of work practices, which seems to be less intensive than in other industrialised countries. Recent OECD studies (2001f; 2001g, pp. 64-67) reveals how ICT-penetration goes hand-in-hand with work reorganisation within firms. By measuring work reorganisation as the incidence of new practices (teamwork, job rotation schemes, employee involvement, flatter management, etc.), Italy appears to lag behind considerably in both the introduction of ICT and the adoption of new workplace practices. At the other extreme of the country sample, the United States and the United Kingdom have high ICT penetration and also a high incidence of new work practices (see Figure A1.1). 


\section{A1.6 Impact on productivity}

Delays in building infrastructures for Internet, e-commerce and e-government together with a lag in R\&D and skilled human resources have been the main complementary factors of the observed lag in the diffusion of ICT within the firms. This technological lag, observed at aggregate level, can only in part be attributable to a specific sectoral composition of production. A relative rigidity of work organisation and protective policies regarding labour and product markets have created conditions for old production and commercial practices to persist on the markets. As a consequence, during the period 1996-1998, Italy registered a decrease in multifactor productivity (MFP), whereas other European countries and particularly the United States have been obtaining substantial productivity gains. (A positive correlation between growth rates in MFP and ICT shares in productive capital stock can be observed in Figure A1.2.) 
Table A1.1. Indicators of relative size of the ICT sector in Italy and other G7 countries

\begin{tabular}{|c|c|c|c|c|c|c|c|}
\hline & ITA & FRA & GER & UK & JPN & CAN & US \\
\hline \multicolumn{8}{|l|}{ ICT-CONSUMING SECTOR, 1996 unless otherwise noted } \\
\hline ICT expenditure as \% of GDP, 1992-1999 & 4.2 & 5.8 & 5.2 & 8.0 & 6.0 & 7.5 & 8.0 \\
\hline Share of ICT in total productive capital stock & 2.1 & 3.2 & 3.0 & 5.2 & 2.3 & 5.0 & 7.4 \\
\hline Share of ICT in non-residential gross fixed capital formation & 9.6 & 10.9 & 10.9 & 18.3 & 8.1 & 16.2 & 19.9 \\
\hline \multicolumn{8}{|l|}{ Penetration of ICT: } \\
\hline - PC's per 100 inhabitants, 1999 & 11 & 22 & 26 & 28 & 25 & 40 & 65 \\
\hline - Internet hosts per 1000 inhabitants, September 1999 & 9 & 13 & 20 & 35 & 19 & 76 & 160 \\
\hline - Secure servers per million inhabitants, March 2000 & 11 & 18 & 35 & 55 & 15 & 87 & 170 \\
\hline - Telecom. access path per 100 inhabitants, 1999 & 99.1 & 92.7 & 87.4 & 96.6 & 99.5 & 88.1 & 101.4 \\
\hline \multicolumn{8}{|l|}{ ICT-PRODUCING SECTOR, 1998} \\
\hline Share in business sector value added & 5.8 & 5.3 & 6.1 & 8.4 & 5.8 & 6.5 & 8.7 \\
\hline - Manufacturing ICT & 1.1 & 1.4 & 2.1 & 1.9 & 3.5 & 1.8 & 2.6 \\
\hline - Telecommunications & 3.2 & 2.0 & 2.6 & 2.4 & 1.6 & 2.6 & 2.8 \\
\hline - Other ICT services & 1.6 & 1.9 & 1.5 & 4.1 & 0.7 & 2.2 & 3.3 \\
\hline Share in business sector employment & 3.5 & 4.0 & 3.1 & 4.8 & 3.4 & 4.6 & 3.9 \\
\hline - Manufacturing ICT & 1.0 & 1.4 & 1.2 & 1.3 & 2.0 & 1.1 & 1.4 \\
\hline - Telecommunications & 0.9 & 1.0 & 0.7 & 0.8 & 0.4 & 1.2 & 1.1 \\
\hline - Other ICT services & 1.6 & 1.6 & 1.2 & 2.7 & 1.1 & 2.3 & 1.5 \\
\hline Share of high-skilled ICT workers in total occupations & 1.1 & 1.7 & 1.5 & 2.0 & - & - & 2.4 \\
\hline \multicolumn{8}{|l|}{ EXTERNAL TRADE IN ICT, 1997} \\
\hline Export ratio (exports as \% of domestic production) & 10.3 & 27.0 & 26.4 & 21.0 & 19.7 & 21.9 & 11.1 \\
\hline - Manufacturing ICT & 38.3 & 64.2 & 66.6 & 88.1 & 27.8 & 66.7 & 29.2 \\
\hline - Telecommunications & 1.6 & 2.2 & 4.4 & 4.3 & 1.2 & 8.7 & 1.3 \\
\hline - Other ICT services & 0.4 & 1.4 & 2.8 & 1.4 & 2.1 & 3.3 & 0.8 \\
\hline Import penetration (imports as \% of domestic demand ${ }^{\star}$ ) & 15.3 & 28.1 & 28.6 & 21.1 & 10.2 & 34.1 & 14.4 \\
\hline - Manufacturing ICT & 49.1 & 65.5 & 68.5 & 88.4 & 14.2 & 80.5 & 35.7 \\
\hline - Telecommunications & 2.5 & 2.4 & 6.6 & 5.1 & 1.6 & 8.4 & 2.8 \\
\hline - Other ICT services & 1.0 & 1.3 & 4.0 & 0.5 & 5.0 & 1.8 & 0.1 \\
\hline Exports - imports as $\%$ of exports + imports & -22.1 & -2.7 & -5.7 & -0.2 & 36.5 & -29.6 & -14.5 \\
\hline - Manufacturing ICT & -21.6 & -2.8 & -4.3 & -1.3 & 39.9 & -34.7 & -14.9 \\
\hline - Telecommunications & -21.4 & -2.4 & -20.7 & -8.1 & -11.4 & 2.0 & -35.7 \\
\hline - Other ICT services & -43.0 & 3.4 & -17.4 & 51.3 & -42.3 & 30.9 & 78.9 \\
\hline Exports - Imports as \% of domestic production & -5.9 & -1.5 & -3.2 & -0.1 & 10.5 & -18.5 & -3.8 \\
\hline - Manufacturing ICT & -21.1 & -3.7 & -6.0 & -2.3 & 15.9 & -70.7 & -10.2 \\
\hline - Telecommunications & -0.9 & -0.1 & -2.3 & -0.8 & -0.3 & 0.3 & -1.5 \\
\hline - Other ICT services & -0.6 & 0.1 & -1.2 & 0.9 & -3.0 & 1.6 & 0.7 \\
\hline
\end{tabular}


DSTI/DOC(2002)13

Table A1.2. Average annual percentage growth of volume investment in the business sector, 1995-2000

\begin{tabular}{|c|c|c|c|c|c|c|c|}
\hline & ITA & FRA & GER & UK & JPN & CAN & US \\
\hline \multicolumn{8}{|c|}{ (Calculated on values deflated using national price indexes) } \\
\hline IT equipment & 12.4 & 21.7 & 16.0 & 13.5 & 11.3 & 34.8 & 32.4 \\
\hline Communication equipment & 6.6 & 11.2 & 6.7 & 10.4 & 16.8 & 11.5 & 16.2 \\
\hline Software & 5.8 & 14.0 & 10.3 & 2.0 & -0.9 & 13.7 & 16.6 \\
\hline \multicolumn{8}{|c|}{ (Calculated on values deflated using harmonised price indexes) } \\
\hline IT equipment & 30.9 & 31.6 & 31.2 & 28.0 & 24.4 & 38.9 & 32.4 \\
\hline Communication equipment & 11.7 & 11.4 & 8.7 & 11.9 & 11.3 & 12.7 & 16.2 \\
\hline Software & 11.0 & 18.6 & 10.9 & 7.1 & 1.1 & 14.6 & 16.6 \\
\hline
\end{tabular}

Figure A1.1. New work practices and ICT shares on productive capital

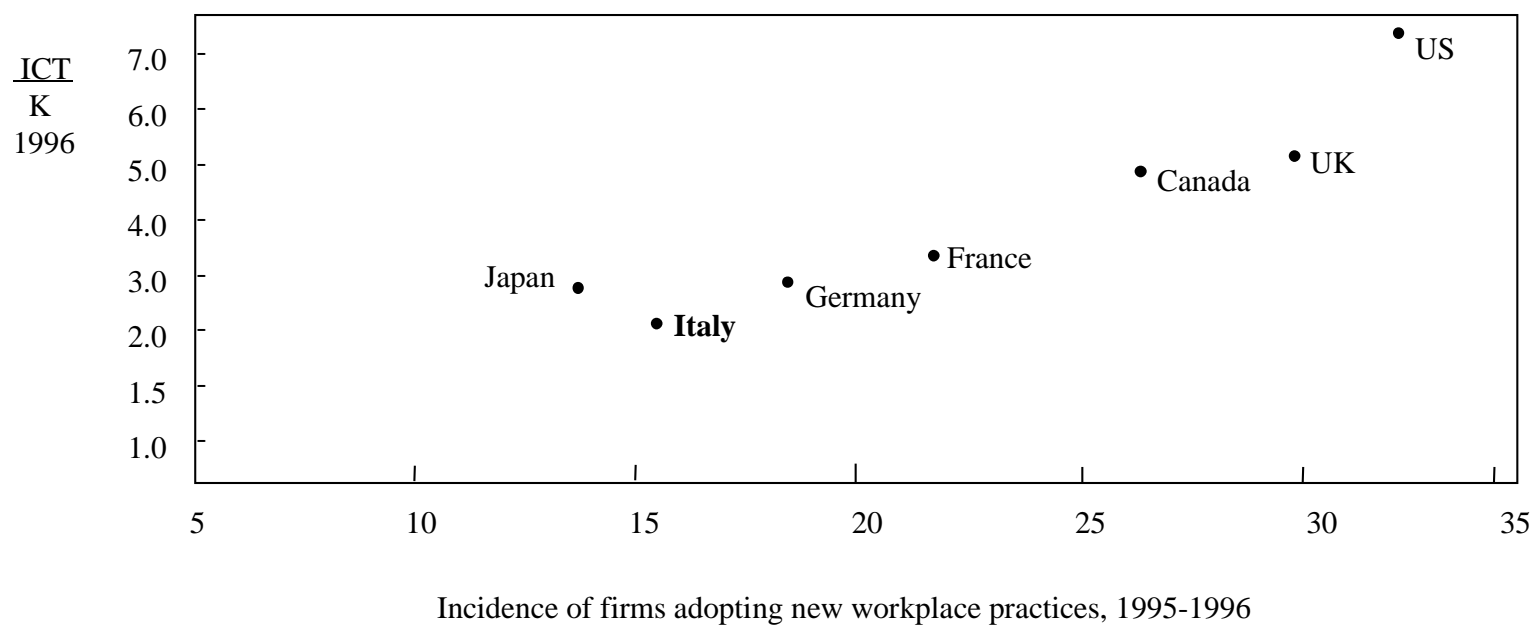

Source: Schreyer (2000), OECD (2001f) (2001g). 
DSTI/DOC(2002)13

Figure A1.2. Multifactor productivity (MFP) average growth rates in 1996-1998 and ICT shares in productive capital stock in 1996 (percentage)

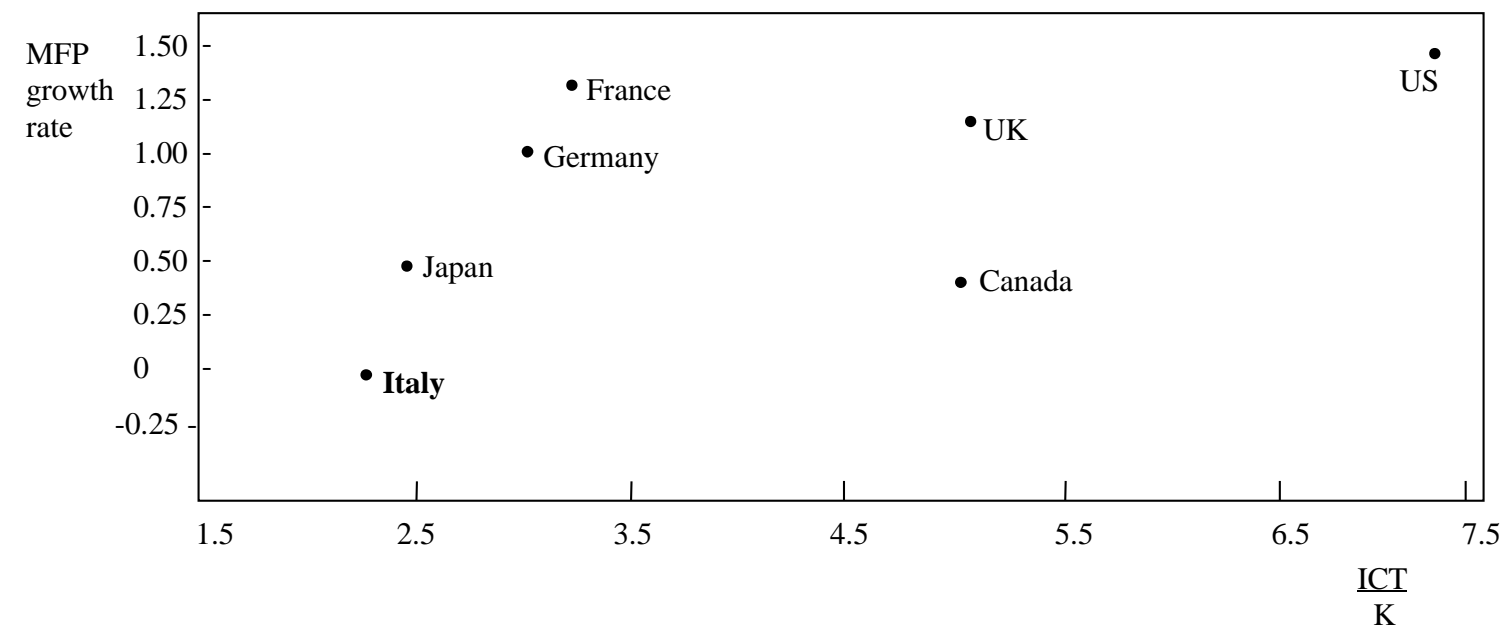

Source: Schreyer (2000). 
DSTI/DOC(2002)13

\section{ANNEX 2. ISTAT'S SURVEYS ON ECONOMIC ACCOUNTS OF ENTERPRISES IN ITALY}

A detailed survey on economic and financial accounts of enterprises is carried out annually in Italy by ISTAT. This survey is intended to cover all enterprises operating in Italy with at least 20 employees until 1997 and at least 100 employees from 1998 to the present date. The survey is conducted by following the normative guidelines of the $4^{\text {th }}$ EEC Directive scheme under the Italian national Law No. 69 of 26 March 1990 and the national Legislative Decree No. 127 of 9 April 1991 (see, for example, ISTAT, 1998). ${ }^{26}$

The survey collects data concerning profit-and-loss accounts and balance sheets. Moreover, information regarding employment, investment, personnel costs and certain regional items is also collected. Although the data collection is aimed at covering the universe of enterprises falling within the established range, there is a non-response problem. Several procedures are used in order to prevent or integrate missing data.

The total population of Italian enterprises with at least 20 employees was around 68000 firms in 1997. In that year and the previous year, the data collected were related also to R\&D and ICT expenses and capital stocks. The respondent enterprises were about 27000 . As for small enterprises with less than 20 employees, a sample survey was carried out annually with some information about ICT obtained at the aggregate level. After 1997, the statistical burden on enterprises was reduced in order to decrease their administrative costs. The questionnaire for large enterprises is, however, still very heavy to be filed accurately.

Since 1998, the survey collects data about all enterprises with at least 100 employees and the number of respondent enterprises was consequently reduced to nearly 3700 . Because of this limitation, many series were interrupted, especially those regarding small and medium-sized enterprises. The survey based only on sampling that previously had been carried out for enterprises with less 20 employees was extended also to larger enterprises by increasing the threshold from a maximum of 20 employees to a maximum of 99 employees. Table A2.1 shows the shares of enterprises with 20 to 99 employees and those with at least 100 employees on total enterprises, for some of the main economic variables.

A major continuity in the time series was maintained for large enterprises, especially for the information relevant to R\&D and ICT investments. The questionnaire of sample surveys that collect data about enterprises with less than 100 employees does not ask the interviewees to provide the necessary information to measure and estimate R\&D expenses and acquisition of ICT.

Table A2.2 presents a scheme of the available information about ICT in the ISTAT's annual surveys over the years. A complete set of homogeneous information about ICT hardware and software in capital stocks at book value and investments in larger enterprises available for the period 1996-2000. It is, however, to be noted that the number of respondent enterprises decrease dramatically from over 27000 in the surveys carried out in 1996 and 1997 to less than 3700 in the survey that took place in 2000. Very limited information or no information at all about the ICT is available for enterprises with less than 100 employees in the ISTAT survey after 1997.

26. The dataset constructed from the ISTAT annual surveys on economic accounts of enterprises is part of a larger Statistical Information System on Enterprises (SISSIEI) being developed by ISTAT itself that intends to integrate all available statistical information on specific statistical units (technically, all the survey data in this system can be linked at firm level via firm codes). 
Table A2.1. Enterprises with between 20 and 100 employees in the ISTAT's annual survey, 1997

Percentage shares on total enterprises

\begin{tabular}{|lccccccc|}
\hline $\begin{array}{c}\text { Enterprise size } \\
\text { (number of } \\
\text { employees) }\end{array}$ & $\begin{array}{c}\text { Number of } \\
\text { enterprises }\end{array}$ & Sales & $\begin{array}{c}\text { Value } \\
\text { Added }\end{array}$ & $\begin{array}{c}\text { Personnel } \\
\text { costs }\end{array}$ & Investment & Employees & $\begin{array}{c}\text { Salaried } \\
\text { employees }\end{array}$ \\
\hline At least 20 & 1.8 & 57.2 & 56.2 & 71.4 & 60.9 & 40.5 & 61.6 \\
At least 100 & 0.2 & 37.7 & 38.0 & 47.5 & 43.1 & 24.1 & 37.4 \\
\hline
\end{tabular}

Table A2.2. Data availability on ICT in the ISTAT's annual surveys on economic accounts of enterprises in Italy, 1993 - 2000

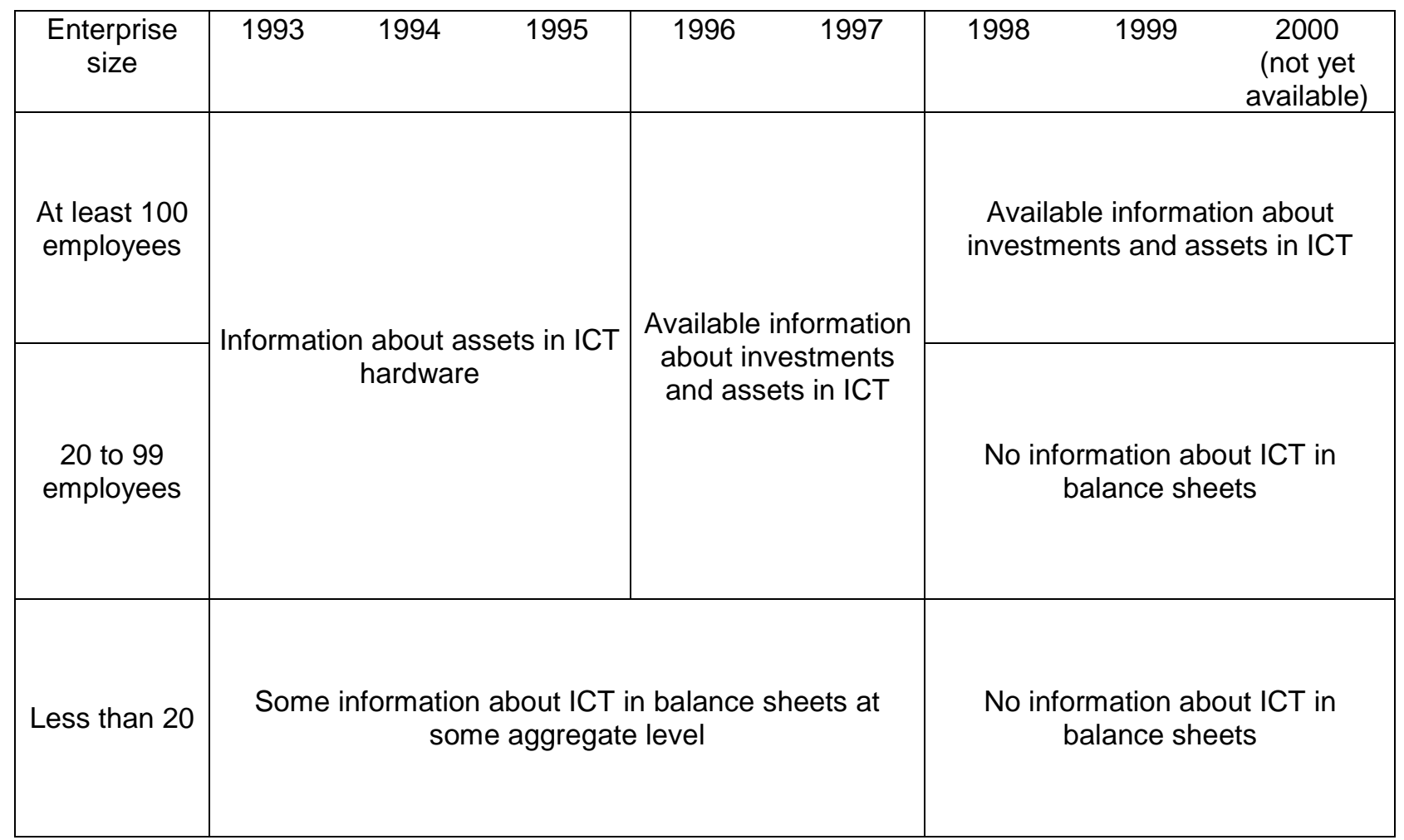


DSTI/DOC(2002)13

\section{ANNEX 3. TECHNICAL EFFICIENCY FROM THE POINT OF VIEW OF LEIBENSTEIN'S THEORY OF X-EFFICIENCY}

Explaining why technically inefficient firms tend to stay on the market is problematic. Competitive markets are expected to push firms' operations to the production frontier destroying all activities that cannot conform to the most efficient practices. Less competitive and monopolistic markets are also expected in several instances to create conditions for the incumbent firms to achieve considerable technological gains. According to the dominant theory, there is little room for technically inefficient firms to exist. The only relevant inefficiency that is considered by mainstream economics is that arising from misallocation of resources caused by distortions of market equilibrium. In this view, firm-level inefficiency may consist mainly in non-optimal allocation of factor inputs on the production frontier.

Empirical evidence has shown, however, that distortions of market equilibrium and the consequent allocative inefficiency may lead to very small welfare losses and very limited increases in costs of production. Firm-level data suggest that higher welfare losses may arise from technical inefficiency in Michael Farell's (1957) sense. This may be the rule rather than the exception even in the long run and the magnitude of its effects exceeds by far that of the allocative inefficiency. Other important types of inefficiency, which may cause technical inefficiency but may have a non-technical origin, were originally indicated by Harvey Liebenstein (1966). At the time of this contribution, no available concept, such as organisational inefficiency or motivational inefficiency, could be used to encompass all the relevant nonallocative inefficiencies that can be found in organisations. Hence, he coined the comprehensive term of "X-(in)efficiency" (see Leibenstein, 1987 and Frantz, 1997 among many other presentations of the Xefficiency theory).

\section{A3.1 The basic elements of the X-efficiency theory}

The concepts of relative technical efficiency (TE) and X-efficiency (XE) are similar although they traditionally stem from different theories of economic performance. Leibenstein (1977), commenting on a paper by Shapiro and Müller (1977) who among other economists have used these terms interchangeably, identified two underlying neo-classical notions that are commonly retained in the concept of TE: the notion of maximising decisions and the view of the firm as a unified and integrated decision-making unit in the same sense in which an individual can be such a decision-making unit. Explanations of XE depart from both these implicit assumptions. "However, under XE theory the static equilibrium of the firm allows [...] for variants in output for the same set of given purchased inputs" (p. 313).

Leibenstein considered his XE theory to be more general than the neo-classical theory of optimising behaviour of firms by seeing the latter as a special case of the former (hence he called it general Xefficiency theory). Following the tabular presentation given in Leibenstein (1978a, p. 204) and reproduced here in Table A3.1, the elements of XE theory can be indicated as follows. The basic unit is the individual rather than the firm or the household thus defining the basis of what is termed micro-micro theory (see also Leibenstein, 1979). In general, individuals are not assumed to maximise income or anything else, but behave according to their personality under various degrees of concern for constraint within what is called selective rationality. The individual effort in performing actions is predetermined in neo-classical theory whereas it is seen to be significantly discretionary by XE theory. Another critical concept, which is absent 
in the neo-classical theory, is human inertia, consisting in the individual tendency to be inert because of utility costs of moving away from present position and utility costs of "setting into" new positions. Interpersonal interactions play some non-negligible role in a reality where individuals are basic units of distinct behaviour. Motivation and effort are discretionary among individuals. They are quite different whether the individual makes the decision for himself as a principal or if he makes it for someone else as an agent. As a consequence, a problem of principal-agent relationship emerges and plays an important role in firms' performance.

Table A3.1. Conventional micro theory and general X-efficiency theory

\begin{tabular}{|l|l|l|}
\hline \multicolumn{1}{|c|}{ Postulates and Basic Variables } & Conventional Micro Theory & General X-Efficiency Theory \\
\hline 1. Psychology & . Maximisation or minimisation & . Selective rationality \\
2. Firm activity contracts & . Given & . Incomplete \\
3. Units & . Households and firms & . Individuals \\
4. Effort & . Assumed given & . Discretionary variable \\
5. Interpersonal interactions & . None & . Some \\
6. Inert areas & . None & . Important variable \\
7. Agent-principal relationship & . Identity of interests & . Differential interests \\
8. Market structure & . Given & . Depends on effort \\
9. Motivation & . Implicitly constant & . Variable \\
\hline
\end{tabular}

Different pressures, external or internal to the firms, may condition the individual decisions and their effort level according to the Yerkes-Dodson Law. When external pressure is low, as in the case of monopoly power, inefficient techniques associated with XE may be combined with relatively low labour input prices. Therefore, the total average total costs of production may turn out to be as equally competitive as those obtainable using the most efficient techniques associated with higher labour input prices.

In competitive markets, external pressure compels the firms to meet the cost competitiveness in different ways. Under these conditions, depending on internal pressure level, firms may exhibit an environment where individuals are more or less inclined to put much effort in maximising output. Firms operating with less efficient techniques may survive and be cost effective by combining technical inefficiency with relatively low wages. Because of the incomplete nature of labour contracts, where payment is specified while effort generally is not, disutility of effort and other reasons, an inert area surrounds the existing levels of effort and wages. Leibenstein defines these areas as areas of choice that cannot be "penetrated". However, as shown in Figure A3.1, a pure Prisoners' Dilemma Problem arises within these firms with both effort and wages being confined at a minimum level (Leibenstein, 1982, 1987). However, certain levels of effort and wages are guaranteed by existing conventions, thus permitting an equilibrium within the inert area surrounding point $c$. This theory offers a basis to explain why technically efficient firms may continue to operate in the long run even in highly competitive markets.

\section{A3.2 Technical efficiency and $X$-efficiency}

The technical efficiency concept in the context of X-efficiency theory is described by Leibenstein (1978b) in these terms: "In transforming inputs into outputs the owner-manager presumably has to choose a 'technique of production'. [...] It is true that we may visualise the transformation of inputs into outputs as involving the choice of a technique of production, but something much more important is involved" (p.11). The choice of techniques is a significant area of performance that is not only a matter of 
engineering, as elementary textbook of economics claim, but is a "host of opportunities for new economic decisions" (p. 12) during the process of production. The details of the output and technique decisions have to be worked out by the individuals involved who put forth effort. Detailed effort decisions are made all along the way and are these decisions that determine the performance and growth of the economy in the long run. Performance may differ according to the type of principal-agent relationship referred to above and distribution of responsibility and motivation of agents within the production activity.

Technical inefficiency and welfare losses due to X-inefficiency may be represented as in Figure A3.2, which is an adaptation of the usual exposition in this field (see, for example, Button and Weyman-Jones, 1994, pp. 86-87). Let us consider, for simplicity, the case of constant returns to scale. Technical inefficiency can be shown in the left-hand portion of Figure A3.2, where all possible best-practise inputoutput combinations, not necessarily known to the firm, are represented for the case of two factor inputs (see Leibenstein, 1978b, pp. 115-117). At given relative input-prices, the cost-minimising production would occur at $\mathrm{N}$, whereas in fact the firm's production occurs at the inefficient point $\mathrm{R}$. In order to assess the relative TE of the firm, we have to net out from the relative cost level the relative allocative efficiency (AE) due to a different factor intensity of $\mathrm{R}$ with respect to $\mathrm{N}$. This can be done by comparing the technique in $\mathrm{R}$ with that in $\mathrm{Q}$, which shows the same factor ratio as in $\mathrm{R}$ and is a best-practise technique as well as N. The distance PQ can be attributed to allocative inefficiency, whereas the distance QR can be interpreted as a pure technical inefficiency. The ratio between the minimum level and the actual level of the average cost of production can then be decomposed as follows: $\mathrm{OP} / \mathrm{OR}=(\mathrm{OP} / \mathrm{OQ}) \cdot(\mathrm{OQ} / \mathrm{OR})$, where $\mathrm{OP} / \mathrm{OQ}$ is attributable to $\mathrm{AE}$ and $\mathrm{OQ} / \mathrm{OR}$ is attributable to TE.

\section{Figure A3.1. The Prisoner's Dilemma Problem: Leibenstein's analysis of intrafirm productivity}

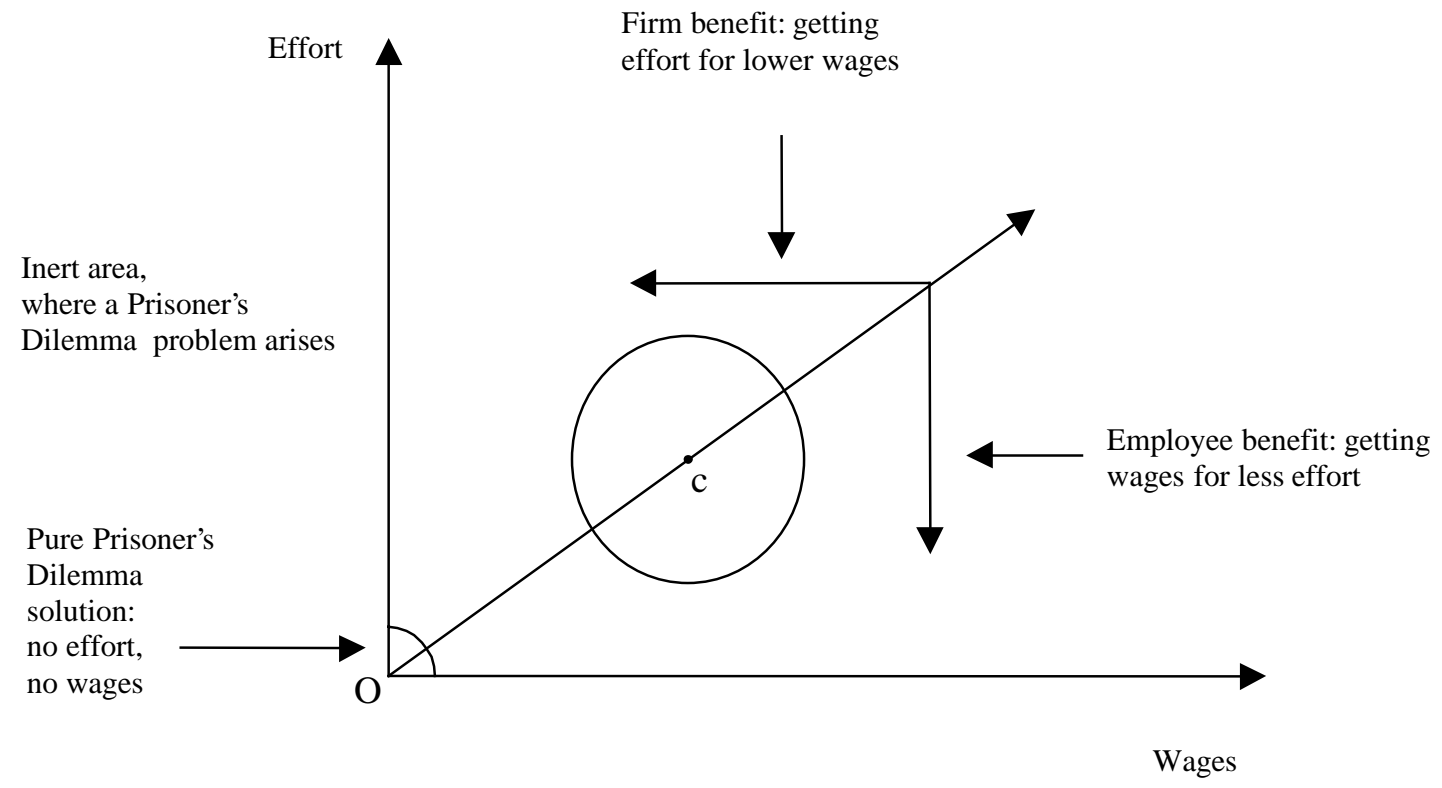

Source: Leibenstein (1987, p. 934). 
The right-hand portion of Figure A3.2 represents X-efficiency loss in the context of other welfare losses. The X-inefficient firm with low external pressure and monopoly power not attempting to keep its marginal cost at the minimum level MC, when confronting with its actual marginal cost curve $\mathrm{MC}^{*}$, will set the output price at P1. This results in a Harberger (1954) deadweight loss of $\mathbf{A}$ and a Posner (1975)-Tullock (1967)-Bhagwati (1982) rent-seeking loss of B. The welfare differences between the X-inefficient MC* and the X-efficient MC are: (i) $\mathbf{C}$, the X-inefficiency loss at the price P1; (ii) $\mathbf{D}$, the additional allocative loss because the output price is not set equal to the $\mathrm{X}$-inefficient $\mathrm{MC}^{*}$ cost level; and (iii) $\mathbf{E}$, the additional allocative loss because the output price is not set equal to lowest possible cost level MC.

Figure A3.2. Technical efficiency and X-efficiency
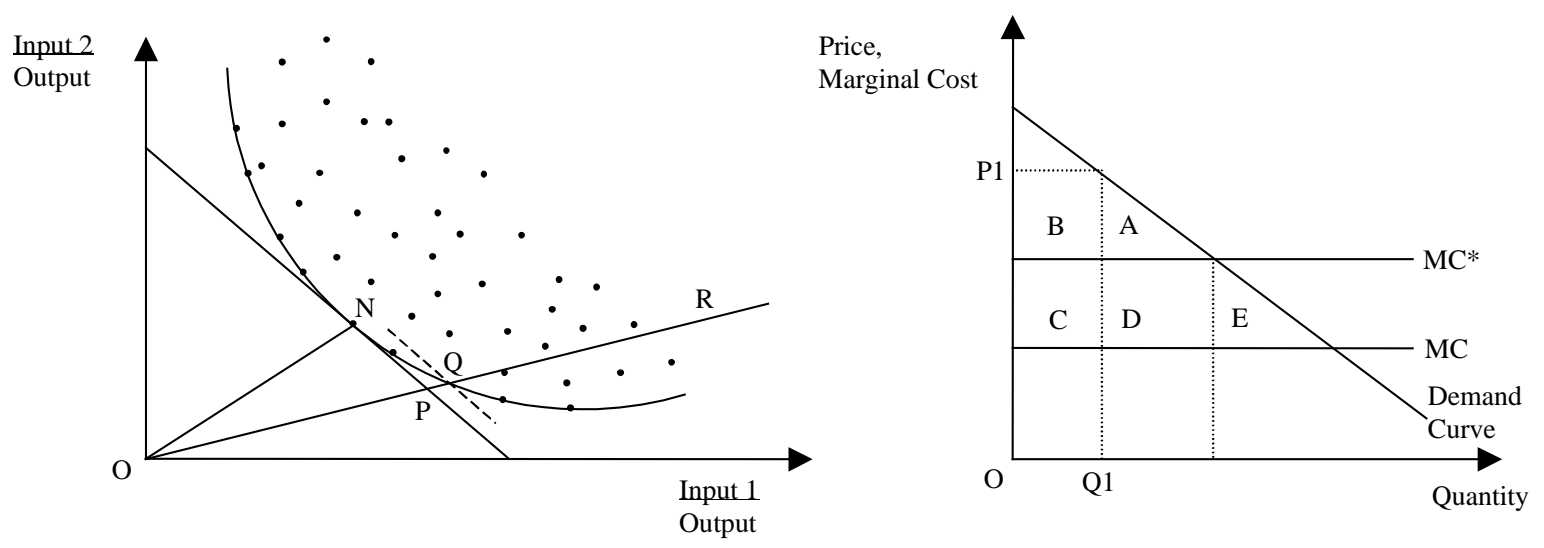

Source: Button and Weyman-Jones (1994, p. 87).

\section{A3.3 New technologies affecting X-efficiency and technical efficiency}

The general XE theory may help to explain how TE may depend on technological change and investments in new technologies. As Leibenstein (1978b, pp. 114-115) noted, there are several reasons why the degree of XE, and hence TE, should change when there is a change in the techniques of production. He mentioned the following: (i) tastes may lead individuals further from the maximising mix of activities under one technique than under another; (ii) work co-ordination and discipline may be greater for the new techniques than for the old; (iii) the old techniques may be efficient as well as the new ones, but are more rigid and may detrimental to the synchronisation of new activities; (iv) personnel selection under the old techniques may be inappropriate under the new techniques; $(v)$ the morale aspects of the work situation may change under the new techniques; (vi) there may be a different trade-off between effort and increase in labour productivity between the new techniques and the old (with possible reactions in one of opposite possible directions consisting in less effort to maintain labour productivity constant or higher effort to meet potential rewards in rising productivity).

An increase in $\mathrm{XE}$ is a consequence of a process similar to learning by doing. The return of a new technology may be significantly conditioned by the resulting change in XE. Initial low levels of XE may discourage investments because entrepreneurs are trapped in an inert area with a vicious circle of nonincreasing profits and low technological investments. It is therefore left to the empirical analysis of the particular case to determine which is the net result in terms of TE and consequent economic returns. 


\section{A3.4 Measuring and partitioning X-efficiency}

In order to reveal, measure and partition TE within the XE theoretical framework, a best-practice frontier defined over observed most efficient production units could be considered with no restrictive hypotheses about producers' behaviour. Non-parametric methods, such as data envelopment analysis, are seen to be good candidates for measurement from the point of view of XE theory because they introduce minimal $a$ priori behavioural assumptions. Leibenstein and Maital (1992) suggest that "DEA merits consideration as a primal method for measuring and partitioning X-inefficiency" (p. 428) and "X-efficiency is based on what has been termed the max/nonmax postulate, which allows for, but never precludes, maximising behaviour. By assuming that at least some decision-making units are successfully practising maximisation, while others may not be, DEA provides a useful set of scalar measures that enable the quantitative comparison of inefficient agents with efficient ones" (pp. 432-433). 


\section{ANNEX 4. MEASURING TECHNICAL EFFICIENCY BY MEANS OF DATA ENVELOPMENT ANALYSIS}

Data envelopment analysis is a linear programming method used to measure the relative technical performance of production units where in the presence of multiple outputs and/or multiple inputs the lack of data on prices or other types of weight needed for aggregation makes comparisons difficult ${ }^{27}$. It implements and generalises to the multiple output/multiple input case Farell's (1957, p. 254) single output/single input technical efficiency measure ${ }^{28}$. The original idea is to identify the best-practice production frontier as the piece-wise-linear convex hull that can be formed by referring to the most efficient production points in the space of outputs and inputs and to measure the distance from this frontier of each production unit in the examined sample.

Although a number of studies have proposed mathematical programming methods to apply Farell's idea in the generalised case (see, for example, Boles, 1966 and Afriat, 1972), it was not until the paper of Charnes, Cooper and Rhodes (1978), in which the term "data envelopment analysis" was coined, that the DEA methodology became widely known and developed further by an increasing number of studies in many fields of application ${ }^{29}$. DEA is now a well known tool in the field of operational research and, as Diewert and Mendoza (1995, p. 2) noted, belongs to an area of analysis to which economists usually refer as the "nonparametric approach to production theory" (see, for example, Hanoch and Rothschild, 1972, Diewert and Parkan, 1983, and Varian, 1984) and the "measurement of the efficiency of production" (see, for example, Farell, 1957, Afriat, 1972, Färe and Lovell, 1978, Färe, Grosskopf and Lovell, 1985, and Lovell, 1993).

The methodology was initially confined to cases of constant returns to scale and was input-oriented (asking by what extent the factor inputs can be proportionally reduced for a given level of output in order to achieve full technical efficiency). The constant-returns-to-scale DEA model is typically referred to as the CCR model after the original contribution of Charnes, Cooper and Rhodes (1978). The variable returns to scale DEA model was developed by Banker, Charnes and Cooper (1984) and after their contribution it is usually referred to as the BCC model. Output-oriented versions of DEA (asking by what degree the output can be expanded for a given factor inputs in order to achieve full technical efficiency) were also developed under both constant- and variable-returns-to-scale models ${ }^{30}$.

DEA is concentrated on technical efficiency measurement. It does not deal with the other concept of efficiency that is widely known as "allocative efficiency". Technical efficiency and allocative efficiency sum up to what is usually defined as "economic or cost efficiency". Since from a cost minimising

27. See Dyson, Thanassoulis and Boussofiane (1990) and Diewert and Mendoza (1995) for a similar definition of DEA.

28. Farell $(1957$, p. 254) recognized that his concept of technical efficiency was similar to the concept of coefficient of resource utilization defined by Debreu (1951).

29. See Seiford (1996), Coelli, Prasada Rao, and Battese (1998, pp. 133-181), Cooper, Seiford and Tone (2000), Sengupta (2000), and Thanassoulis (2001) for descriptions of the DEA technique in various versions.

30. The input- and output-oriented measures of the relative technical efficiency coincide in the case of constant returns to scale (see Färe and Lovell, 1978). 
perspective the allocative efficiency can be interpreted as an input-price component of cost efficiency, it is not usually considered when the quantity-based concept of productivity is examined ${ }^{31}$.

Technical efficiency measures can be depicted in the right-hand side of Figure A4.1 in the case of constantreturns to scale and in the left-hand side of the same Figure A4.1 in the case of decreasing returns to scale. The technology is represented, for simplicity, by the one-output one-input piece-wise linear frontier. For the inefficient production unit operating at point $\mathrm{P}$, the Farell input-oriented measure of TE corresponds to $\mathrm{AB} / \mathrm{AP}$, while the output-oriented measure of TE corresponds to $\mathrm{CP} / \mathrm{CD}$. As it can be seen in Figure A4.1, the input- and output-oriented measures are equivalent $(\mathrm{AB} / \mathrm{AP}=\mathrm{CP} / \mathrm{CD})$ only with a constant returns to scale technology.

Figure A4.1. Data envelopment and returns to scale in the one-output/one-input

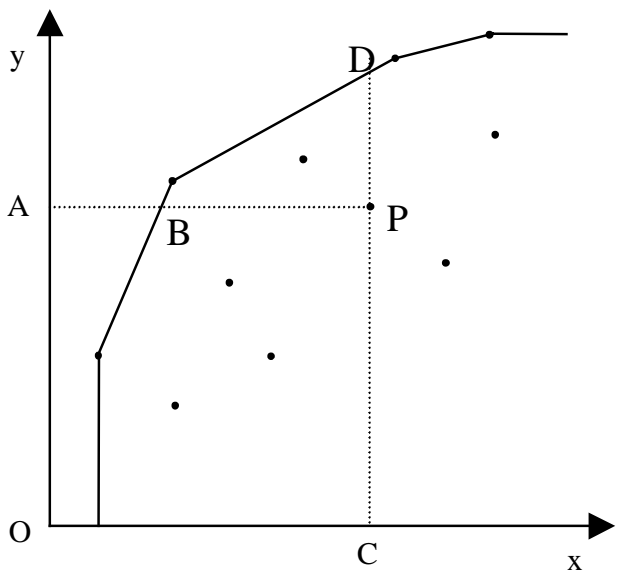

(a) Decreasing returns to scale

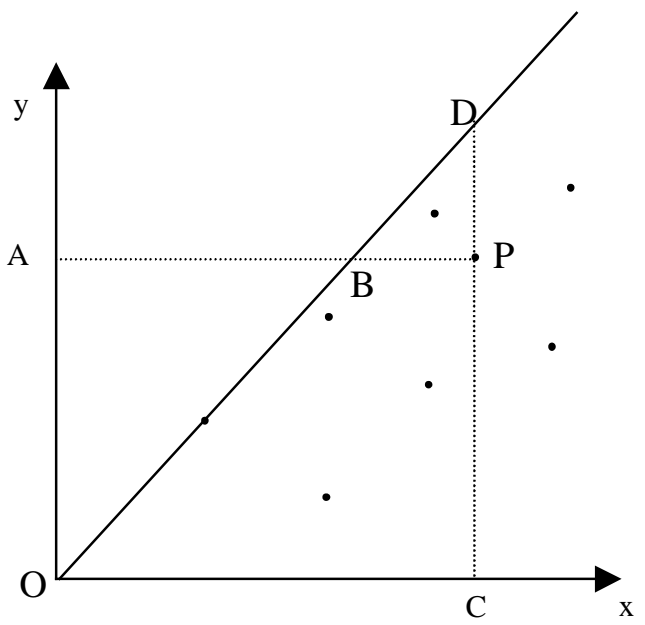

(b) Constant returns to scale

\section{A4.1 Input-oriented DEA models}

Input-oriented DEA models seek to identify technical inefficiency of each production unit of the sample by measuring the maximum proportional reduction in input quantities that would be obtained for given output levels.

\section{A4.1.1 Constant returns to scale}

Starting from the notion of technical efficiency defined basically as an output/input ratio, DEA has been originally defined under the hypothesis of constant returns to scale, which makes comparisons between production units not affected by the activity scale. The methodology evolved from specifications of the model in ratio form, to the so-called "multiplier" form and the most used "envelopment" form.

\section{(a) Ratio form of DEA}

The usual measure of efficiency is given by the output/input ratio. In the case of multiple outputs and/or multiple inputs, the measurement of relative efficiency was developed by Farell and Fieldhouse (1962) by

31. Farell (1957, p. 255) introduced "overall efficiency", what is now termed "economic or cost efficiency", and "price efficiency" what is now usually referred to as "allocative efficiency" (see Figure A2.1 in Annex 2). 
constructing a hypothetical reference unit as a weighted average of efficient units and using it as "benchmark" for comparisons of inefficient units. Technical efficiency was in this way expressed as a ratio between a weighted sum of outputs and a weighted sum of inputs, where the weights, if not available, are the unknowns to be found ${ }^{32}$. Under the assumption of constant returns to scale, DEA was therefore originally developed in ratio form, which finds, for the $i$ th production unit, the maximum ratio given by $\mathbf{u}_{i}^{\prime} \mathbf{y}_{i} / \mathbf{v}_{i}^{\prime} \mathbf{x}_{i}$, where $\mathbf{u}_{i}$ is the $M$-order column vector of output weights, $\mathbf{v}_{i}$ is the $K$-order column vector of input weights, $\mathbf{y}_{i}$ is the $M$-order column vector of outputs, and $\mathbf{x}_{i}$ is the $K$-order column vector of inputs. The weights $\mathbf{u}_{i}$ and $\mathbf{v}_{\boldsymbol{i}}$ can be interpreted as shadow prices (note that the production units may value differently the single outputs and inputs). The optimal numerical values of these weights, when unknown, are found by solving the following mathematical programming problem ${ }^{33}$ :

$$
\begin{aligned}
& \max _{\mathbf{u}_{i} \mathbf{y}_{i}} \quad \mathbf{u}_{i}^{\prime} \mathbf{y}_{i} / \mathbf{v}_{i}^{\prime} \mathbf{x}_{i} \\
& \text { subject to } \mathbf{u}_{i}^{\prime} \mathbf{y}_{1} / \mathbf{v}_{i}^{\prime} \mathbf{x}_{1} \leq 1 \\
& \mathbf{u}_{i}^{\prime} \mathbf{y}_{2} / \mathbf{v}_{i}^{\prime} \mathbf{x}_{2} \leq 1 \\
& \mathbf{u}_{i}^{\prime} \mathbf{y}_{N} / \mathbf{v}_{i}^{\prime} \mathbf{x}_{N} \leq 1 \\
& \mathbf{u}_{i} \geq \mathbf{0}_{M} \\
& \mathbf{v}_{i} \geq \mathbf{0}_{\boldsymbol{K}}
\end{aligned}
$$

\section{(b) Multiplier form of DEA}

The optimising numerical values for $\mathbf{u}_{i}$ and $\mathbf{v}_{i}$ involve that the efficiency measure for the $i$ th production unit given by the ratio of the weighted sum of outputs and the weighted sum of inputs is maximised, subject to the constraints that all the efficiency measures must be less than or equal to one. In order to avoid that the solution of optimal values for $\mathbf{u}_{i}$ and $\mathbf{v}_{i}$ be overdetermined (that is if $\left(\mathbf{u}^{*}, \mathbf{v}^{*}\right)$ is a solution, then for any arbitrary $\alpha$ also $\left(\alpha \mathbf{u}_{i}{ }^{*}, \alpha \mathbf{v}_{i}{ }^{*}\right)$ is a solution), the additional normalising constraint $\mathbf{v}^{\prime} \mathbf{x}_{i}=1$ can be imposed. Moreover, the DEA model (A4.1) is a fractional linear programming problem. In order to apply the solving methods of linear programming, it is first necessary to convert the model into linear form. This is can be done by reformulating (A4.1) in a form, which has become known as the multiplier form of the DEA:

$$
\begin{array}{r}
\max _{\mathbf{u}_{i}, v_{i}} \quad \mu_{i}^{\prime} \mathbf{y}_{i} / v_{i}^{\prime} \mathbf{x}_{i} \\
\text { subject to } \quad v_{i}^{\prime} \mathbf{x}_{i}=1 \\
\mu_{i}^{\prime} \mathbf{y}_{1}-v_{i}^{\prime} \mathbf{x}_{1} \leq 0 \\
\mu_{i}^{\prime} \mathbf{y}_{2}-v_{i}^{\prime} \mathbf{x}_{2} \leq 0
\end{array}
$$

32. The most natural aggregation weights are prices, which can be used, if data are available, to construct aggregate index numbers for multiple quantities.

33. The exposition of the mathematical formulation of DEA given here follows Coelli, Prasada Rao and Battese (1998, pp. 140-142; pp. 150-152; pp. 158). 


$$
\begin{aligned}
\mu_{i} \mathbf{y}_{N}-v_{i} \mathbf{x}_{N} & \leq 0 \\
\mu_{i} & \geq \mathbf{0}_{\boldsymbol{M}} \\
v_{i} & \geq \mathbf{0}_{\boldsymbol{K}}
\end{aligned}
$$

where the $\mu_{i}$ and $v_{i}$ can be interpreted as normalised shadow prices.

\section{(c) The envelopment form of DEA}

The envelopment form dual to the multiplier form (A4.2) is obtained as follows:

$$
\begin{aligned}
\min _{\theta_{i}, \lambda_{i}} & \theta_{i} \\
\text { subject to } \mathbf{Y} \lambda_{i}-\mathbf{y}_{i} & \geq \mathbf{0}_{M} \\
\theta_{i} \mathbf{x}_{i}-\mathbf{X} \boldsymbol{\lambda}_{i} & \geq \mathbf{0}_{K} \\
\lambda_{i} & \geq \mathbf{0}_{N}
\end{aligned}
$$

where $\mathbf{X}$ and $\mathbf{Y}$ are, respectively, is the $K \times N$ input matrix and the $M \times N$ output matrix formed by input and output data for all $N$ production units, $\lambda_{i}$ is a $N$-order column vector of constants and $\theta_{i}$ is a scalar representing the input-oriented measure of technical efficiency for the $i$ th production unit and satisfying the inequality $\theta_{i} \leq 1$ (the value of $\theta_{i}$ equal to 1 indicates a point on the frontier and that the production activity is technically efficient in Farell's sense). To find the efficiency score for all production units, the linear programming problem must be solved $N$ times, once for each of the production units in the sample. The envelopment form (A4.3) is generally preferable to the multiplier form (A4.2) because it is more parsimonious in the constraints $(K+M<N+1)$.

\section{A4.1.2 Variable returns to scale}

A more general case that includes the possibility of variable returns to scale on the efficient frontier can be derived from the constant-returns-to-scale LP programming problem (A4.3) by adding the convexity constraint $\mathbf{N 1} \lambda_{i}=1$ (with $\mathbf{N 1}$ being an $N$-order column vector of elements equal to 1 ) thus ensuring that an inefficient production unit is compared only with other units of similar size:

$$
\begin{aligned}
\min _{\theta_{i}, \lambda_{i}} & \theta_{i} \\
\text { subject to } \mathbf{Y} \lambda_{i}-\mathbf{y}_{i} & \geq \mathbf{0}_{M} \\
\theta_{i} \mathbf{x}_{i}-\mathbf{X} \lambda_{i} & \geq \mathbf{0}_{K} \\
\mathbf{N} \mathbf{1}^{\prime} \cdot \lambda_{i} & =1 \\
\lambda_{i} & \geq \mathbf{0}_{N}
\end{aligned}
$$


The convexity introduced by the additional constraint imposes an envelopment of the data points which is tighter than that obtained by assuming constant-returns-to-scale and therefore leads to efficiency scores that are higher than those obtained by the latter. This difference between the efficiency scores can be interpreted as scale inefficiency, since the examined production unit is not seen to operate at the optimal scale. However, even if the efficiency measures may differ between the two methods, the input- and output-oriented models identify the same set of most efficient firms.

\section{A4.2. Output-oriented DEA models}

Output-oriented DEA models seek to identify technical inefficiency of each production unit of the sample by measuring the maximum proportional increase in output quantities that would be obtained for given input levels. When there are scale inefficiencies, different measures of this increase in output quantities may be obtained by DEA models assuming constant-returns-to-scale and those assuming variable-returnsto-scale.

\section{A4.2.1 Constant returns to scale}

When the technology of production exhibits constant returns to scale, the appropriate envelopment form of the DEA linear programming problem for the $i$ th production unit has the following specification:

$$
\begin{aligned}
& \max _{\phi_{i}, \lambda_{\mathrm{i}}} \phi_{i} \\
& \text { subject to } \quad \mathbf{Y} \lambda_{i}-\phi_{i} \mathbf{y}_{i} \geq \mathbf{0}_{M} \\
& \mathbf{x}_{i}-\mathbf{X} \lambda_{i} \geq \mathbf{0}_{K} \\
& \lambda_{i} \geq \mathbf{0}_{N}
\end{aligned}
$$

where $1 \leq \phi_{i}<\infty$. The value $\left(\phi_{i}-1\right)$ is the (proportional) increase in output(s) that could be obtained by the $i$ th production unit with the input quantities held constant. The DEA LP problem (A4.5) is solved separately for each individual production unit in the sample examined.

\section{A4.2.2 Variable returns to scale}

The variable-returns-to-scale version of the output-oriented envelopment form of DEA LP problem for the $i$ th production unit is obtained by adding the convexity constraint $\mathbf{N} 1 \cdot \lambda_{i}=1$ to (A4.5):

$$
\max _{\phi_{i}, \lambda_{\mathrm{i}}} \phi_{i}
$$

$$
\text { subject to } \quad \begin{aligned}
\mathbf{Y} \lambda_{i}-\phi_{i} \mathbf{y}_{i} & \geq \mathbf{0}_{M} \\
\mathbf{x}_{i}-\mathbf{X} \lambda_{i} & \geq \mathbf{0}_{K} \\
\mathbf{N} \mathbf{1}^{\prime} \lambda_{i} & =1 \\
\lambda_{i} & \geq \mathbf{0}_{N}
\end{aligned}
$$




\section{A4.2.3 The input- and output-oriented measures of technical efficiency}

The input-oriented measure of technical efficiency of the $i$ th production unit is given by the scalar $\theta_{i}$. The output-oriented measure of technical efficiency $\left(\mathrm{TE}_{i}\right)$ of the $i$ th production unit is given by:

$$
\mathrm{TE}_{i}=1 / \phi_{i}
$$

$\mathrm{TE}_{i}$ varies between zero and one $\left(0<\mathrm{TE}_{i} \leq 1\right.$, where $\mathrm{TE}_{i}=1$ means that the $i$ th production unit is fully efficient and operates on the best-practice frontier). In the constant-return-to-scale model, the outputoriented efficiency score is exactly equal to the inverse of the input-oriented efficiency score, that is $1 / \phi_{i}=\theta_{i}$. As we have seen in Figure A4.1, this is not necessarily true in the case of other returns to scale assumptions. 


\section{REFERENCES}

Afriat, S.N. (1972), "Efficiency Estimation of Production Functions", International Economic Review, 13(2), 568-598.

Aigner, Dennis J. C. A. Knox Lovell and Peter Schmidt (1977), "Formulation and Estimation of Stochastic Frontier Production Function Models", Journal of Econometrics, 6(1), 21-37.

Assinform (2001), Rapporto Assinform sull'occupazione nel settore dell'informatica $e$ delle telecomunicazioni in Italia. Terza edizione, Milan, Italy. (Available at: http://www.assinform.it .)

Atzeni, Gianfranco and Oliviero A. Carboni (2001), "The Economic Effects of Information Technology: Firm Level Evidence from the Italian Case", presented at the Conference organised by Centro Ricerche Economiche Nord-Sud (CRENoS), University of Cagliari, at Cagliari, Italy, July 6-7 (Available at: http://www.crenos.unica.it/news/preliminarcnr.html.)

Balk, Bert M. M.C. Paul de Boer and Sonja Greve (2001), "The Average Efficiency of Firms within an Industry: An Application of Data Envelopment Analysis", presented at the XIII International Conference on Input-Output Techniques, University of Macerata, Italy, August 21-25 (Available at: http://policy.rudgers.edu/cupr/indexlg.htm)

Banker, R.D. A. Charnes and W.W. Cooper (1984), "Some Models for Estimating Technical and Scale Inefficiencies in Data Envelopment Analysis", Management Science, 30, 1078-1092.

Baudchon, Hélène and Olivier Brossard (2001), "Croissance et technologies de l'information en France et aux Etats-Unis ”, Revue de l'OFCE, No. 76 (January), 53-115.

Beede, David N. and Sabrina L. Montes (1997), "Information Technology's Impact on Firm Structure: A Cross-Industry Analysis", U.S. Department of Commerce, Economics and Statistics Administration, Office of Business and Industrial Analysis, ESA/OPD 97-3, Washington, D.C. (Available at the URL http://www.esa.doc.gov/58/esa/InformationTechnology\%27sImpact.htm)

Berndt, Ernst R. Catherine J. Morrison and L.S. Rosenblum (1992), "High-Tech Capital, Formation and Labor Composition in US Manufacturing Industries: An Exploratory Analysis", NBER Working Paper 4010, March, Cambridge, MA.

Berndt, Ernst R. and Catherine J. Morrison (1995), "High-Tech Capital Formation and Economic Performance in U.S. Manufacturing Industries: An Exploratory Analysis", Journal of Econometrics, 65(1), 9-43.

Bhagwati, Jagdish N. (1982), "Directly Unproductive, Profit-Seeking (DUP) Activities", Journal of Political Economy 90: 988-1002.

Black, Sandra E. and Lisa M. Lynch (1997), "How to Compete: The Impact of Workplace Practices and Information Technology on Productivity", NBER Working Paper 6120, August, Cambridge, MA. 
Boles, J.N. (1966), "Efficiency Squared - Efficiency Computation of Efficiency Indexes", Proceedings of the 39th Annual Meeting of the Western Farm Economics Association, pp. 137-142.

Brynjolfsson, Erik and Lorin M. Hitt (1995), "Information Technology as a Factor of Production: The Role of Differences Among Firms", Economics of Innovation and New Technology, 3(3-4), 183-199.

Brynjolfsson, Erik and Lorin M. Hitt (2000), "Beyond Computation: Information Technology, Organisational Transformation and Business Performance", Journal of Economic Perspectives, 14(4), Fall, 23-48.

Brynjolfsson, Erik and Brian Kahin (2000), Understanding the Digital Economy, Cambridge, MA, The MIT Press.

Brynjolfsson, Erik and Shinkyu Yang (1996), "Information Technology and Productivity: A Review of the Literature", Advances in Computers, 43(1), 179-214.

Bugamelli, Matteo and Patrizio Pagano (2001), "ICT and Factor Complementarities in the Italian Manufacturing", presented at the Conference organised by Centro Ricerche Economiche Nord-Sud (CRENoS), University of Cagliari, at Cagliari, Italy, July 6-7. (Available at: http://www.crenos.unica.it/news/preliminarcnr.html)

Button, Kenneth J. and Thomas G. Weyman-Jones (1994), "X-Efficiency and Technical Efficiency", Public Choice, 80(1-2), pp. 83-104.

Caselli, Francesco and Wilbur John Coleman II (2000), “The World Technology Frontier”, NBERWorking Paper 7904, Cambridge, MA.

Caselli, Francesco and Wilbur John Coleman II (2001), "Cross-Country Technology Diffusion: The Case of Computers", American Economic Review (Papers and Proceedings), 91(2), May, 328-335.

Charnes, A. W.W. Cooper; and E. Rhodes (1978), "Measuring the Efficiency of Decision Making Units", European Journal of Operation Research, 2, 429-444.

Chennels, L. and J. van Reenen (2001), "Technical Change and the Structure of Employment and Wages: A Survey of the Econometric Evidence", in N. Greenan, Y. Lhorty, J. Mairesse (eds.), The Puzzling Relations between the Computer and the Economy, The MIT Press, Cambridge, MA.

Choi, Soon-Yong and Andrew B. Whinston (2000), The Internet Economy: Technology and Practice, SmartEcon Publishing, Austin, Texas.

Coelli, T.J. (1996), "A Guide to DEAP Version 2.1: A Data Envelopment Analysis (Computer) Program", University of New England, Department of Econometrics, CEPA Working Paper No. 8/96, Armidale, NSW 2351, Australia. (Available at:

http://www.une.edu.au/econometrics/cepa2.htm\#software)

Coelli, T.J. D.S. Prasada Rao and George E. Battese (1998), An Introduction to Efficiency and Productivity Analysis, Boston, MA, Kluwer Academic Publishers.

Colecchia, Alessandra (2001), "The Impact of Information and Communication Technology on Output Growth”, STI Working Paper, Paris, OECD, forthcoming. 
Colecchia, Alessandra and Paul Schreyer (2001), "ICT Investment and Economic Growth in the 1990s: Is the United States a Unique Case? A Comparative Study of Nine OECD Countries", STI Working Paper 2001/7, OECD, Paris (Available at: http://www1.oecd.org/dsti/sti/prod/sti_wp.htm)

Cooper, William W. Lawrence M. Seyford and Kaoru Tone (2000), Data Envelopment Analysis: A Comprehensive Text with Models, Applications, References and DEA-Solver Software, Kluwer Academic Publishers, Boston, MA.

Council of Economic Advisors (2000), Economic Report of the President, Washington, D.C., United States Government Printing Office.

Council of Economic Advisors (2001), Economic Report of the President, Washington, D.C., United States Government Printing Office.

Crafts, Nicholas (2002), "The Solow Productivity Paradox in Historical Perspective", CEPR Discussion Paper No. 3142, Center for Economic Policy Research, London.

Cummins, J. David and Hongmin Zi (1998), "Comparison of Frontier Efficiency Methods: An Application to the U.S. Life Insurance Industry", Journal of Productivity Analysis, 10(2): 131-152.

Daveri, Francesco (2000), "Is Growth in Europe an ICT-Story Too?", presented at the XII Villa Mondragone International Economic Seminar "Knowledge Economy, Information Technologies and Growth", organised by CEIS, University of Rome "Tor Vergata", Monte Porzio Catone (Rome), June 26-28.

Daveri, Francesco (2001), "Information Technology and Growth in Europe", presented at the Conference organised by Centro Ricerche Economiche Nord-Sud (CRENoS), University of Cagliari, at Cagliari, Italy, July 6-7. (Available at: http://www.crenos.unica.it/news/preliminarcnr.html .)

Debreu, Gerard (1951), “The Coefficient of Resource Utilisation”, Econometrica, 19, 273-292.

Diewert, W. Erwin and C. Parkan (1983), "Linear Programming Tests of Regularity Conditions for Production Functions" in W. Eichhorn, R. Henn, K. Neumann and R.W. Shephard (eds), Quantitative Studies on Production and Prices, Physica Verlag, Wien, pp. 131-158.

Diewert, W. Erwin and M.N.F. Mendoza (1995), "Data Envelopment Analysis: A Practical Alternative?", Discussion Paper No. DP 95-30, Department of Economics, The University of British Columbia, Vancouver, B.C., Canada.

Dyson, R.G. E. Thanassoulis and A. Boussofiane (1990), "Data Envelopment Analysis" in L.C. Hendry and R.W. Eglese (eds.), Tutorial Papers in Operational Research, Operational Research Society.

Färe, Rolf, Shawna Grosskopf and C.A. Knox Lovell (1985), The Measurement of Efficiency of Production, Kluwer-Nijhoff Publishing, Boston, Dordrecht, Lancaster.

Färe, Rolf and C.A. Knox Lovell (1978), "Measuring the Technical Efficiency of Production”, Journal of Economic Theory, 19, 150-162.

Farrell, M.J. (1957), "The Measurement of Productive Efficiency", Journal of the Royal Statistical Society", Series A, CXX, Part 3, 253-290. 
Farell, M. J. and M. Fieldhouse (1962), "Estimating Efficient Production Functions Under Increasing Returns to Scale", Journal of Royal Statistical Society, Series A 125, 252-267.

Federcomin (2000), ICT - Le figure professionali, Milan. (Available at: http://www.federcomin.it/home.html .)

Federcomin (2001), "Il mercato ICT. Osservatorio a settembre 2001", I quaderni di Federcomin, n. 2, Confindustria.

Ferri, Giovanni Marzio Galeotti and Ottavio Ricchi (2001), "Inside the 'Magic Box': Internet and the Growth of Small and Medium-Sized Enterprises. Some Evidence from Italy", presented at the XIII Villa Mondragone International Economic Seminar "Financial Markets, the New Economy and Growth", organised by CEIS, University of Rome "Tor Vergata", Monte Porzio Catone (Rome), June 25-26.

Frantz, Roger S. (1997), X-Efficiency: Theory, Evidence and Applications, Second Edition, Kluwer Academic Publishers, Boston, MA, Dordrecht, London.

Gill, Gurmukh, Kan Young, Dennis Pastore, Jesus Dumagan and Isaak Turk (1997), "Economy-Wide and Industry-Level Impact of Information Technology", U.S. Department of Commerce, Economics and Statistics Administration, Office of Business and Industrial Analysis, ESA/OPD97-3, Washington, D.C. (Available at: http://www.esa.doc.gov/508/esa/Economy-Wide.htm .)

Gordon, Robert J. (2000), "Does the 'New Economy' Measure Up to the Great Inventions of the Past?", Journal of Economic Perspectives, 14(4), 49-74.

Greenan, Nathalie, Jacques Mairesse and Agnes Topiol-Bensaid (2001), "Information Technology and Research and Development Impacts on Productivity and Skills: Looking for Correlations on French Firm Level Data", NBER Working Paper 8075, Cambridge, MA.

Greenspan, Alan (2000), "Business Data Analysis", Remarks before the New York Association for Business Economics, New York, NY (via videoconference), Federal Reserve Board, Washington, D.C., June 13, available at: http://www.federalreserve.gov/boarddocs/speeches/2000/20000613.htm

Hanoch, G. and M. Rothschild (1972), "Testing the Assumptions of Production Theory: A Nonparametric Approach", Journal of Political Economy, 80, 256-275.

Harberger, A.C. (1954), "Monopoly and Resource Allocation", American Economic Review Proceedings, 44: 77-87.

Hatzichronoglu, T. (1997), "Revision of the High-Technology Sector and Product Classification", STI Working Paper 1997/2, OECD, Paris. (Available at: http://wwwl.oecd.org/dsti/sti/prod/sti_wp.htm)

Hitt, L. and E. Brynjolfsson (2001), "Information Technology, Organisational Transformation and Business Performance", in N. Greenan, Y. Lhorty, J. Mairesse (eds.), The Puzzling Relations between the Computer and the Economy, Cambridge, MA, The MIT Press.

Hollingsworth, Bruce (1999), "Software Reviews. Data Envelopment Analysis and Productivity Analysis: A Review of the Options", Economic Journal, 109(June), F458-F462. 
Hulten, Charles R. (2001), “Total Factor Productivity : A Short Biography”, in Charles R. Hulten, Edwin R. Dean, and Michael J. Harper (eds.), New Developments in Productivity Analysis, Chicago, Michigan, University of Chicago Press for the National Bureau of Economic Analysis.

INSEE (2001), "La diffusion des nouvelles technologies de l'information et la communication dans l'économie", L'Économie française 2000-2001, Paris.

International Data Corporation (1998), Digital Economy - The Global Information Economy, IDC, Framingham, MA. (Available at: http://www.idc.com)

ISTAT (1998), "Rilevazione sul Sistema dei Conti delle Imprese. Anno 1997. Guida per la compilazione del questionario ISTAT/SCI", Rome, Italy.

Jorgenson, Dale W. (2001), "Information Technology and the U.S. Economy" (Presidential Address delivered at the one-hundred and thirteenth meeting of the American Economic Association), American Economic Review, 91(1), 1-32.

Jorgenson, Dale W. and Kevin J. Stiroh (2000a), "Raising the Speed Limit: U.S. Economic Growth in the Information Age", Brookings Papers on Economic Activity, 1(1), 125-211.

Jorgenson, Dale W. and Kevin J. Stiroh (2000b), "U.S. Economic Growth and the Industry Level", American Economic Review, Vol. 90 (2), 161-7.

Kiley, Michael T. (1999), "Computers and Growth with Costs of Adjustment: Will the Future Look Like the Past?", Federal Reserve Board, Finance and Economic Discussion Series Paper 1999-36. (Available at: http://www.federalreserve.gov/pubs/feds/1999/index.html)

Koopmans, T.C. (1951), "An Analysis of Production as an Efficient Combination of Activities", in T.C. Koopmans (ed. by), Activity Analysis of Production and Allocation, Cowles Commission for Research in Economics, Monograph No. 13, Wiley, New York.

Lehr, Bill and Frank Lichtenberg (1999), "Information Technology and Its Impact on Productivity: FirmLevel Evidence from Government and Private Data Sources, 1977-1993", Canadian Journal of Economics, 32(2), 335-362.

Leibenstein, Harvey (1966), "Allocative Efficiency vs. 'X-Efficiency"”, American Economic Review, 56(3), 392-415.

Leibenstein, Harvey (1977), "X-Efficiency, Technical Efficiency, and Incomplete Information Use: A Comment", Economic Development and Cultural Change, 25(2), pp. 311-16.

Leibenstein, Harvey (1978a), "X-Inefficiency Xists - Reply to an Xorcist", American Economic Review, 68(1), pp. 203- 211.

Leibenstein, Harvey (1978b), General X-Efficiency Theory and Economic Development, Oxford University Press, New York, London, and Toronto.

Leibenstein, Harvey (1979), "A Branch of Economics is Missing: Micro-Micro Theory", Journal of Economic Literature 17(June), 477-502.

Leibenstein, Harvey (1982), “The Prisoners' Dilemma in the Invisible Hand: An Analysis of Intrafirm Productivity", American Economic Review, Papers and Proceedings 72(2), 92-97. 
Leibenstein, Harvey (1987), "X-efficiency Theory“, in John Eatwell, Murray Milgate, and Peter Newman (eds), The New Palgrave. A Dictionary of Economics, The Macmillan Press Limited, London, Volume 4, pp. 934-935.

Leibenstein, Harvey and Shlomo Maital (1992), "Empirical Estimation and Partitioning of X-Inefficiency: A Data Envelopment Approach", American Economic Review, May 1992, 82(2), pp. 428-433.

Licht, Georg and Dietmar Moch (1999), "Innovation and Information Technology in Services", Canadian Journal of Economics, 32(2), 363-383.

Lichtenberg, Frank (1995), "The Output Contribution of Computer Equipment and Personnel: A Firm Level Analysis", Economics of Innovation and New Technology, 3, 201-217.

Lovell, C.A. Knox (1993), "Production Frontiers and Productive Efficiency", in Harold O. Fried and C.A. Knox Lovell, Shelton S. Schmidt (eds), The Measurement of Productive Efficiency. Techniques and Applications, Oxford University Press, Oxford, pp. 3-67.

Mairesse, J.; G. Cette and Y. Kocoglu (2000), «Les technologies de l'information et de communication en France : diffusion et contribution à la croissance », Economie et Statistique, No.9/19, 339-340.

McGuckin, Robert H. and Kevin J. Stiroh (1998), "Computers Can Accelerate Productivity Growth", Issues in Science and Technology, Summer.

McGuckin, Robert H. and Kevin, J. Stiroh (2001), "Do Computers Make Output Harder to Measure?", Journal of Technology Transfer.

Meeusen, Wim and Julien van den Broek (1977), "Efficiency Estimation from Cobb-Douglas Production Functions with Composed Error", International Economic Review, 18(2), 435-444.

Milana, Carlo (1999), "Proposal for the Definition of Industries within the KLEM Project", paper presented at the working meeting of the KLEM Consortium, 9-10 December, Centre of Economic and Business Research (CEBR), Copenhagen.

Morrison, Catherine J. and Ernst R. Berndt (1991), "Assessing the Productivity of Information Technology Equipment in U.S. Manufacturing Industries", NBER Working Paper 3583, Cambridge, MA.

NSF (National Science Foundation) (2000), Science and Engineering Indicators 2000, Arlington, VA. (Available at: http://www.nsf.gov/sbe/srs/seind00/pdfstart.htm)

OECD (1996), Technology, Productivity and Job Creation, Vol. 1 and Vol. 2, OECD, Paris.

OECD (2000a), Measuring the ICT Sector, Paris. (Available at the Internet URL http://www.oecd.org/dsti/sti/it/prod/measuring_ict.htm.)

OECD (2000b), A New Economy? The Changing Role of Innovation and Information Technology in Growth, Paris.

OECD (2001a), Measuring Productivity. OECD Manual. Measurement of Aggregate and Industry-Level Productivity Growth, Paris.

OECD (2001b), "Productivity and Firm Dynamics: Evidence from Microdata", OECD Economic Outlook, Vol. 2001/1, No. 69 (June), Paris, Chapter VII, pp. 209-223. 
OECD (2001c), “OECD Input-Output Database”, Paris.

OECD (2001d), OECD Science, Technology and Industry Scoreboard. Towards a Knowledge-Based Economy, Paris. (Charts and Figures available at: http://www1.oecd.org/publications/e-book/922001-04-1-2987; for general information, see http://www.oecd.org/sti/statistical-analysis)

OECD (2001e), "Firm-Level Data in OECD Member Countries: An Inventory of Existing Resources", Paris, mimeo. (Information available at: http://petra/istat.it)

OECD (2001f), Knowledge, Work Organisation and Economic Growth, Paris.

OECD (2001g), The New Economy: Beyond the Hype, Paris.

OECD (2002), "Ongoing Changes in the Business Cycle", OECD Economic Outlook №71, June.

Oliner, Stephen D. and Daniel E. Sichel (2000), "The Resurgence of Growth in the Late 1990s: Is Information Technology the Story?", Journal of Economic Perspectives, 14(4), 3-22.

Oulton, Nicholas (2001), "ICT and Productivity Growth in the United Kingdom", Bank of England working paper, London. (Available at: http://www.bankofengland.co.uk/workingpapers/index.htm ).

Paganetto, Luigi, Leonardo Becchetti and David Andres Londono Bedoya (2000), "IT Investment, Productivity and Efficiency: Evidence at Firm Level Using a Stochastic Frontier Approach", presented at the XII Villa Mondragone International Economic Seminar "Knowledge Economy, Information Technologies and Growth", organised by CEIS, University of Rome "Tor Vergata", Monte Porzio Catone (Rome), June 26-28.

Pilat, Dirk and Frank C. Lee (2001), "Productivity Growth in ICT-Producing and ICT-Using Industries: A Source of Growth Differentials in the OECD?", STI Working Paper 2001/4, OECD, Paris. (Available at: http://www1.oecd.org/dsti/sti/prod/sti_wp.htm)

Posner, R.A. (1975), "The Social Costs of Monopoly and Regulation", Journal of Political Economy 83: 807-827.

Scarpetta, S., E.J. Bartelsman, P. Portugal and F. Schivardi (2002), "Comparative Analysis of Firm Demographics and Survival: Micro-Level Evidence for the OECD Countries", OECD Economics Department Working Paper, Paris, forthcoming.

Schreyer, Paul (1989), "Information and Communication Technology and the Measurement of Real Output, Final Demand and Productivity”, STI Working Paper 1998/2, Paris, OECD. (Available at: http://www1.oecd.org/dsti/sti/prod/sti_wp.htm)

Schreyer, Paul (2000), "The Contribution of Information and Communication Technology to Output Growth: A Study of the G7 Countries", STI Working Paper 2000/2, Paris, OECD. (Available at: http://www1.oecd.org/dsti/sti/prod/sti_wp.htm)

Seiford, L. M. (1996), "Data Envelopment Analysis: The Evolution of the State of the Art (1978-1995)", Journal of Productivity Analysis, 7, 99-138.

Sengupta, Jati K., (2000), Dynamic and Stochastic Efficiency Analysis: Economics and Data Envelopment Analysis, World Scientific Publishing Co., Inc., 
Shapiro, Carl and Hal R. Varian (1999), Information rules, Harvard Business School Press, Boston, MA.

Shapiro, Kenneth H. and Jürgen Müller (1977), "Sources of Technical Efficiency: The Roles of Modernization and Information", Economic Development and Cultural Change, 25(2), 293-310.

Sharma, Khem R., Pingsun Leung and Halina M. Zaleski (1997) "Productivity Efficiency of the Swine Industry in Hawaii: Stochastic Frontier vs. Data Envelopment Analysis", Journal of Productivity Analysis, 8(4), 447-459.

Sichel, Daniel E. (1997), The Computer Revolution: An Economic Perspective, Washington, D.C., Brookings Institution Press. (Available at: http://brookings.nap.edu/books/081577897X/html/index.html)

Siegel, Donald (1997), "The Impact of Computers on Manufacturing Productivity Growth: A MultipleIndicators, Multiple-Causes Approach", Review of Economics and Statistics, 79(1), 68-78.

Solow, Robert M. (1987), “We'd Better Watch Out”, New York Times Book Review, July 12, No. 36.

Stiroh, Kevin J. (2001), "Information Technology and the U.S. Productivity Revival: What Do the Industry Data Say", Staff Report No. 115, Federal Reserve Bank of New York, New York. (Available at: http://www.ny.frb.org/rmaghome/staff_rp/2001/sr115.html)

Thanassoulis, Emmanuel (2001), Introduction to the Theory and Application of Data Envelopment Analysis - A Foundation Text with Integrated Software, Kluwer Academic Publishers, Boston, MA.

Tullock, G. (1966), "The Welfare Cost of Tariffs, Monopolies, and Theft”, Western Economic Journal 5: 224-232.

Uchitelle, L. (2000), "Economic View: Productivity Finally Shows the Impact of Computers", New York Times, 12 March.

United Nations (1968), "International Standard Industrial Classification of All Economic Activities, Second Revision”, Statistical Papers, Series M, No. 4, Rev. 2 (Sales No. E.68.XVII.8), New York.

United Nations (1990), "International Standard Industrial Classification of All Economic Activities, Third Revision”, Statistical Papers, Series M, No. 4, Rev. 3 (Sales No. E.90.XVII.11), New York.

U.S. Department of Commerce (1999), The Emerging Digital Economy II, Economics and Statistics Administration, Washington, D.C. (Available at: http://www.esa.doc.gov/508/esa/USEconomy.htm)

Van Ark, Bart (2001), "The Renewal of the Old Economy: An International Comparative Perspective", STI Working Paper 2001/5, OECD, Paris. (Available at:

http://www1.oecd.org/dsti/sti/prod/sti_wp.htm)

Van der Wiel (2001), "Does ICT Boost Dutch Productivity Growth?", CPB document No. 016, Netherlands Bureau for Economic Policy Analysis, The Hague.

Varian, Hal R. (1984), "The Nonparametric Approach to Production Analysis", Econometrica, 52, 579597.

Webb, Colin (2002), "Knowledge-Based Industries”, STI Working Paper OECD, Paris, forthcoming. 


\section{DSTI/DOC(2002)13}

Whelan, Karl (2000), “Computers, Obsolescence, and Productivity”, Federal Reserve Board, Finance and Economics Discussion Series Paper 2000-6. (Available at:

http://www.federalreserve.gov/pubs/feds/2000/index.html)

World Information Technology and Services Alliance (2000), Digital Planet 2000. The Global Information Economy, WITSA, Vienna, VA. (Executive summary available at: http://www.witsa.org/papers) 